\title{
Dinophysiales (Dinophyceae) no extremo Sul do Brasil (inverno de 2005, verão de 2007)
}

\author{
Lumi Haraguchi ${ }^{1,2}$ \& Clarisse Odebrecht ${ }^{1}$ \\ ${ }^{1}$ Instituto de Oceanografia, Universidade Federal do Rio Grande - FURG, \\ Av. Itália, Km 8, CEP 96201-900, Rio Grande, RS, Brasil, www.furg.br \\ ${ }^{2}$ Autor para correspondência: Lumi Haraguchi, e-mail: lumi_h@yahoo.com.br
}

HARAGUCHI, L. \& ODEBRECHT, C. Dinophysiales (Dinophyceae) in the farthest Southern region of Brazil (Winter 2005, Summer 2007). Biota Neotrop. 10(3): http://www.biotaneotropica.org.br/v10n3/en/ abstract?article+bn01910032010.

\begin{abstract}
The dinoflagellates of the Dinophysiales order are a morphologically diverse and ecologically heterogeneous group that includes autotrophic, mixotrophic and heterotrophic species and others containing endosymbionts or phycotoxin producers. In this research Dinophysis, Ornithocercus, Histioneis and Amphisolenia species have been identified in both coastal and oceanic waters of the Southern region of Brazil next to Santa Marta Grande Cape, SC and Albardão-Chuí, RS. Vertical hauls were performed with plankton nets (20 $\mu \mathrm{m})$ on board of the R. V. Atlântico Sul at 33 oceanographic stations sampled in August/September 2005 (Winter) and February 2007 (Summer). The plankton was fixed with formaldehyde (4\%) and analyzed with the help of an inverted microscope. A total of 43 Dinophysiales species were identified, most of them widely distributed in the coastal, continental and oceanic areas such as Dinophysis acuminata, D. exigua, D. ovata and Histioneis hyalina in the Summer of 2007 and D. acuminata, D. caudata, D. fortii e D. schroederi in the Winter of 2005. The distribution of some species was restricted to the oceanic region under the influence of the Brazil Current as it was observed for Dinophysis dubia, D. exigua, D. schuetti, Histioneis para, Ornithocercus thumii and O. splendidus in the Winter of 2005 and D. similis, D. rapa, H. megalocopa, H. milneri, O. heteroporus and O. splendidus in the Summer of 2007. Six potentially toxic species were registered, Dinophysis acuminata, D. caudata, D. fortii, D. mitra, D. tripos and D. rotundata.
\end{abstract}

Keywords: biodiversity, dinoflagellates, Dinophysis.

HARAGUCHI, L. \& ODEBRECHT, C. Dinophysiales (Dinophyceae) no extremo Sul do Brasil (inverno de 2005, verão de 2007). Biota Neotrop. 10(3): http://www.biotaneotropica.org.br/v10n3/pt/ abstract?article+bn01910032010.

Resumo: Os dinoflagelados da ordem Dinophysiales representam um grupo morfologicamente diverso e ecologicamente heterogêneo, incluindo espécies autotróficas, mixotróficas e heterotróficas, outras contendo endossimbiontes ou ainda produtoras de ficotoxinas. No presente trabalho, foram identificadas as espécies de Dinophysis, Ornithocercus, Histioneis e Amphisolenia em águas costeira e oceânica na região Sul do Brasil, ao largo do Cabo de Santa Marta Grande, SC e Albardão-Chuí, RS. Arrastos verticais foram realizados com rede de plâncton $(20 \mu \mathrm{m})$ à bordo do N. O. Atlântico Sul em 33 estações oceanográficas visitadas em agosto/ setembro de 2005 (inverno) e fevereiro de 2007 (verão). As amostras de plâncton foram fixadas com formol (4\%) e analisadas com o auxílio de microscópio invertido. Ao todo, 43 espécies de Dinophysiales foram identificadas, a maioria com ampla distribuição nas regiões costeira, de plataforma continental e oceânica, como Dinophysis acuminata, D. exigua, D. ovata e Histioneis hyalina no verão de 2007 , e D. acuminata, D. caudata, D. fortii e D. schroederi no inverno de 2005. Algumas espécies apresentaram distribuição restrita à região oceânica, sob influência da Corrente do Brasil, como Dinophysis dubia, D. exigua, D. schuetti, Histioneis para, Ornithocercus thumii e $O$. splendidus no inverno de 2005, e D. similis, D. rapa, H. megalocopa, H. milneri, O. heteroporus e O. splendidus no verão de 2007. Seis espécies potencialmente tóxicas foram encontradas, Dinophysis acuminata, D. caudata, D. fortii, D. mitra, D. tripos e D. rotundata.

Palavras-chave: biodiversidade, dinoflagelados, Dinophysis. 


\section{Introdução}

Os dinoflagelados da ordem Dinophysiales (Lindemann 1928) são marinhos e representam um grupo diverso morfologicamente e ecologicamente. A presença de espécies autotróficas, mixotróficas e heterotróficas (Hallegraeff \& Lucas 1988, Park et al. 2006, Nagai et al. 2008), outras contendo endossimbiontes (Carpenter 2002) ou ainda produtoras de ficotoxinas (Taylor et al. 2004), fazem deste grupo um importante componente do ecossistema marinho, apesar de geralmente ocorrer em baixa abundância. Existe uma grande variabilidade morfológica intra-específica na ordem Dinophysiales, como observado para Dinophysis (Reguera et al. 2007) e Histioneis (Gomez 2007), a qual é explicada pela expressão fenotípica dos indivíduos em suas interações com o ecossistema ou pela idade e fase do ciclo de vida em que os mesmos se encontram. Recentemente, algumas espécies de Dinophysis foram cultivadas com sucesso em laboratório, requerendo a presença de outras microalgas, como no caso de Dinophysis acuminata e D. fortii que apresentam um comportamento heterotrófico e requerem a presença do ciliado Myrionecta rubra, do qual roubam os plastídios (Park et al. 2006, Nagai et al. 2008). A principal forma de reprodução das espécies de Dinophysiales dá-se através de divisão vegetativa, mas o seu ciclo de vida pode ser complexo e algumas morfo-espécies, na realidade, fazem parte do ciclo de vida de outras espécies. Por exemplo, as células ditas pequenas, D. skagi, D. parvula, D. microstrigilisformis, $D$. diegensis e $D$. diegensis var. curvata, representam fases no ciclo de vida possivelmente sexuado, de $D$. acuminata, $D$. rotundata, D. fortii, D. caudata e D. tripos, respectivamente (Reguera 2003, Reguera et al. 2007).

Por esta razão, a identificação morfológica de espécies e até mesmo gêneros se depara com dificuldades e requer a realização de estudos em laboratório e análises genéticas para a sua elucidação. A delimitação dos gêneros Dinophysis e Phalacroma, por exemplo, passa por esta dificuldade. No presente trabalho seguimos a ideia de Balech (1988) e aceitamos Phalacroma (Stein 1883) como sinônimo de Dinophysis (Ehrenberg 1839), com prioridade do último. A diferenciação destes dois gêneros com base no critério da altura do epiteca, além da posição do cíngulo, é por vezes subjetiva, existindo espécies de transição (Balech 1988). Estudos recentes utilizando técnicas de biologia molecular trazem evidências de que Dinophysis e Phalacroma apresentam de fato um grau de parentesco menor, permitindo a sua classificação em gêneros distintos (Jensen \& Daugbjerg 2009).

O presente trabalho tem por objetivo auxiliar na construção do conhecimento sobre a biodiversidade marinha brasileira, em especial sobre as espécies da Ordem Dinophysiales e sua distribuição espacial e temporal em área néritica e oceânica no extremo Sul do Brasil. Nesta região, foram listadas 44 espécies de Dinophysiales no apêndice apresentado em Seeliger et al. (1998), mas ainda existem poucos trabalhos contendo imagens dos organismos. O material coletado à bordo do N. Oc. Meteor (1925-1927) em expedição que abrangeu todo o Oceano Atlântico incluiu algumas estações próximas dessa região (Käsler 1938), e no Atlas de Dinoflagelados do Atlântico Sudoeste (Balech 1988), o limite norte da área coincide com a região do extremo sul do Brasil $\left(32^{\circ} \mathrm{S}\right)$ e se estende até a região da Convergência Antártica. Por outro lado, a distribuição espacial e temporal é desconhecida.

\section{Material e Métodos}

No âmbito do projeto PRONEX-FURG, foram realizados dois cruzeiros à bordo do N. Oc. Atlântico Sul, durante agosto/setembro de 2005 e fevereiro de 2007. Arrastos verticais foram realizados com rede de plâncton (malha de $20 \mu \mathrm{m}$ ) em 33 estações, das quais 15 estavam situadas ao largo do Cabo de Santa Marta Grande, SC (SMG; $28^{\circ} 38^{\prime} 15^{\prime \prime} \mathrm{S}$ e $49^{\circ} 08^{\prime} 20^{\prime \prime} \mathrm{W}$ a $29^{\circ} 28^{\prime} 30^{\prime \prime} \mathrm{S}$ e $\left.49^{\circ} 37^{\prime} 13^{\prime \prime} \mathrm{W}\right)$ e

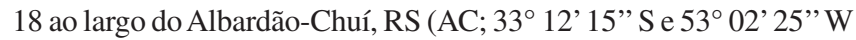
a $34^{\circ} 15^{\prime} 15^{\prime \prime} \mathrm{S}$ e $51^{\circ} 51^{\prime} 53^{\prime} \mathrm{W}$ ). As amostras foram conservadas em formol (4\%). Para que o esforço fosse similar, o mesmo número de estações (15) foi analisado em cada local e distribuídas na área costeira ( $\leq 25 \mathrm{~m}$; três estações), na plataforma continental (25-350 m; nove estações) e na área oceânica ( $\leq 350 \mathrm{~m}$; três estações). De cada amostra, uma alíquota de 4,2 mL foi observada em câmara de sedimentação com o uso de microscópio invertido Axiovert Zeiss 135, os indivíduos da ordem Dinophysiales foram identificados e microfotografias foram obtidas utilizando uma câmera digital Diagnostics, modelo Spot Insight. Os indivíduos foram identificados morfologicamente segundo os trabalhos de Balech (1988), Tomas (1996), Tenenbaum (2006), Gomez (2007) e, em alguns casos, também de Schiller (1933).

\section{Resultados}

\section{Descrição das espécies de Dinophysiales}

Seguem abaixo, a descrição, tamanho e a distribuição das espécies observadas.

\section{AMPHISOLENIA}

\section{Amphisolenia bidentata Schröder (Figura 1)}

Espécie delgada de corpo muito alongado e sub-dividido em uma cabeça anterior onde se localiza o cíngulo; um pescoço estreito onde se localiza o sulco em sua parte ventral; um corpo mais largo adjacente ao pescoço; e um apêndice caudal alongado, ligeiramente curvado para a parte ventral, possuindo dois espinhos antapicais. A epiteca reduzida é levemente convexa.

Tamanho: Comprimento da célula: $848 \mu \mathrm{m}$; Largura da Hipoteca: $21 \mu \mathrm{m}$. Um único indivíduo encontrado.

Distribuição: Somente um indivíduo foi encontrado na plataforma continental de AC no período de verão. Entretanto, de acordo com Balech (1988), a espécie é relativamente frequente, podendo ser abundante em águas da Corrente do Brasil no Oceano Atlântico Sudoeste, ao norte de $40^{\circ} 34^{\prime} \mathrm{S}$ e $52^{\circ} 38^{\prime} \mathrm{W}$.

\section{DINOPHYSIS}

\section{Dinophysis acuminata Claparède \& Lachmann (Figura 15)}

As células possuem uma epiteca reduzida, levemente convexa e achatada. Em vista lateral, apresentam-se elípticas e alargadas dorso-ventralmente. O cíngulo é côncavo na parte dorsal. Aleta cingular anterior desenvolvida e sem costelas. Aleta sulcal esquerda claramente mais curta do que a hipoteca, podendo apresentar ou não irregularidades. Segunda costela mais próxima da primeira do que da terceira. Podem surgir algumas protuberâncias na região antapical.

Tamanho: Comprimento da célula: 33-51 $\mu \mathrm{m}$; Largura da Epiteca: 7-15 $\mu \mathrm{m}$; Largura da Hipoteca: 24-39 $\mu \mathrm{m}$.

Distribuição: No período de inverno, foi encontrada em estações costeiras e oceânicas, em maior número em AC (161 indivídous) do que em CSMG (24 indivíduos). No verão, foi observado um grande número de indivíduos, mas somente em CSMG (342 indivíduos). Balech (1988) registrou a espécie ao sul de $36^{\circ} 30^{\prime} \mathrm{S}$, associada com águas subantárticas. A espécie é conhecida por sua ampla distribuição em águas frias e temperadas.

Produção de toxinas: Produtora de toxinas diarréicas (DSP) do tipo ácido okadaico (Proença et al. 1999, Taylor et al. 2004, Tavares et al. 2009). 

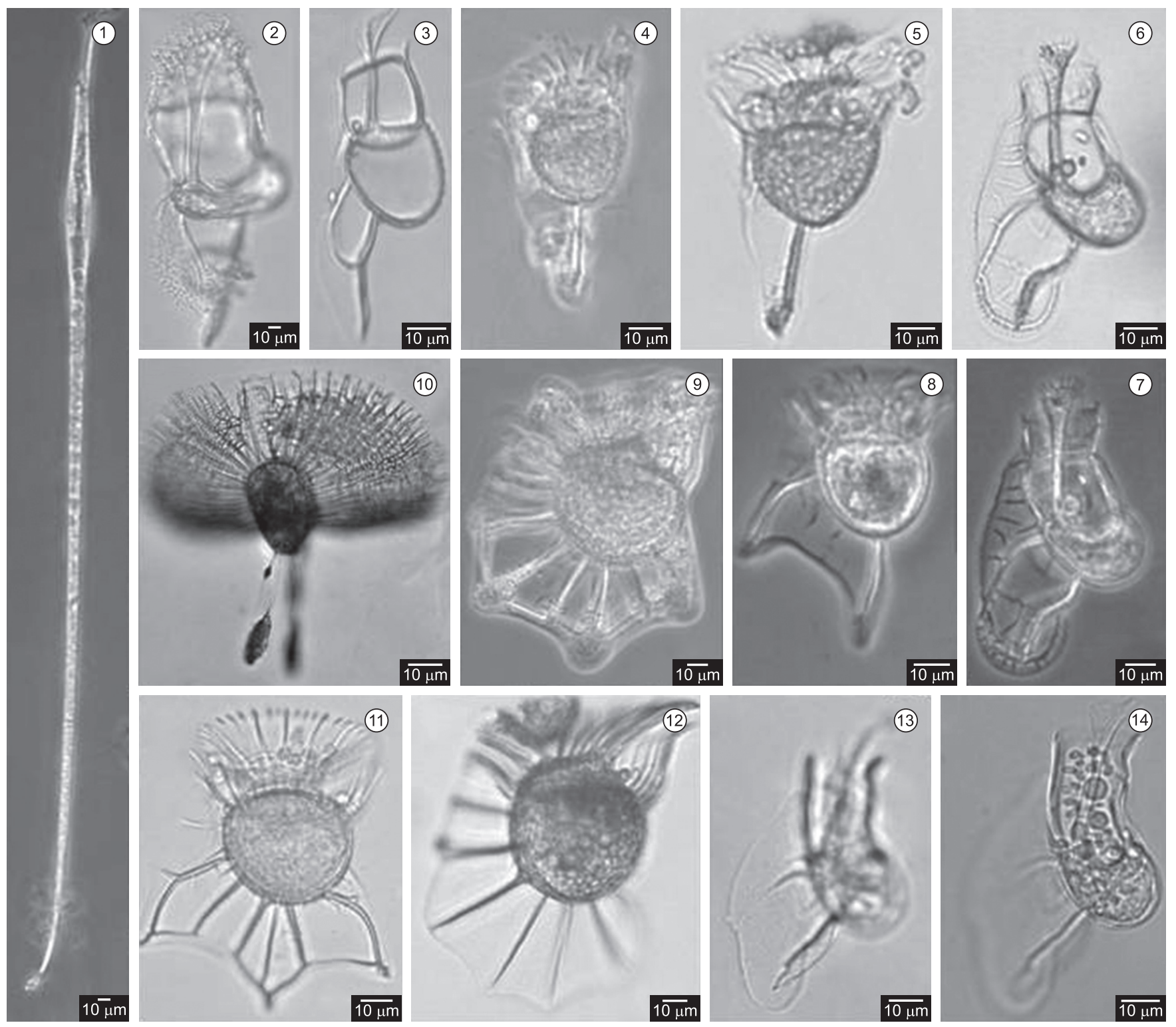

Figuras 1-14. 1) Amphisolenia bidentata; 2) Histioneis cymbalaria; 3) H. hyalina; 4), 5) H. para; 6), 7) H. megalocopa; 8) Ornithocercus heteroporus; 9) O. thumii; 10) O. splendidus; 11) O. magnificus; 12) O. steinii; 13), 14) Histioneis milneri.

\section{Dinophysis amandula Sournia (Figura 47)}

\section{Sin.: Phalacroma ovum Schütt}

Células de tamanho mediano. Em vista lateral, apresentam forma oval. Epiteca alta, regularmente arredondada, às vezes um pouco chata no centro. Cíngulo convexo, seguindo o contorno geral da teca. Aletas cingulares lisas e horizontais. Aleta sulcal esquerda com desenvolvimento homogêneo. A segunda costela fica mais próxima da primeira do que da terceira. Esta última é forte, grande e pode ser um pouco claviforme. Porção retrocostal de borda livre suavemente côncava. Aleta sulcal direita um pouco saliente no nível da segunda costela, mas depois termina em forma triangular. Espécie heterotrófica.

Tamanho: Comprimento da célula: 51-54 $\mu \mathrm{m}$; Largura da Epiteca: 27-40 $\mu \mathrm{m}$; Largura da Hipoteca: 42-46 $\mu \mathrm{m}$.

Distribuição: Foi encontrada na plataforma continental, sob influência de Água Subtropical de Plataforma no período de inverno em AC (1 indivíduo). No verão, ocorreu exclusivamente em CSMG (6 indivíduos) em águas de plataforma e oceânicas. No Oceano Atlântico Sudoeste, pouco frequente na Corrente do Brasil ao norte de $38^{\circ} \mathrm{S}$ (Balech 1988).

Dinophysis amphora Balech (Figura 39)

Célula de tamanho pequeno, em vista lateral com comprimento e largura aproximadamente iguais. Epiteca larga e levemente achatada. Região posterior arredondada. Aletas cingulares lisas e pouco erguidas. Aleta sulcal esquerda bem desenvolvida, principalmente na altura da terceira costela. Aleta sulcal direita grande, alcançando a terceira costela.

Tamanho: Comprimento da célula: $37 \mu \mathrm{m}$; Largura da Epiteca: $23 \mu \mathrm{m}$; Largura da Hipoteca: $35 \mu \mathrm{m}$.

Distribuição: Um único indivíduo foi encontrado na plataforma continental de CSMG no período de verão. Espécie raramente encontrada no Oceano Atlântico Sudoeste em águas oceânicas entre $40^{\circ} 43^{\prime} \mathrm{S}$ e $57^{\circ} 49^{\prime} \mathrm{S}$ (Balech 1988). 


\section{Dinophysis bibulbus Balech (Figura 26)}

Célula oval em vista lateral, larga e um pouco irregular, com o eixo levemente inclinado ventralmente. Borda ventral muito inclinada e algo côncava na parte anterior, antes da segunda costela. Epiteca pequena e achatada. Aletas cingulares anterior e posterior com estrias. Aleta sulcal esquerda de largura moderada e uniforme, arredondada posteriormente, na ausência da terceira costela.

Tamanho: Comprimento da célula: $30 \mu \mathrm{m}$; Largura da Epiteca: $5 \mu \mathrm{m}$; Largura da Hipoteca: $29 \mu \mathrm{m}$. Tamanho bem menor do que aquele observado por Balech (1988) (Comprimento da célula: 41-46 $\mu \mathrm{m}$; Largura de Epiteca: 10-12 $\mu \mathrm{m}$; Largura da Hipoteca: 41-48 $\mu \mathrm{m})$.

Distribuição: O único indivíduo identificado foi encontrado na plataforma continental de AC no período de verão. No Oceano Atlântico Sudoeste, foi raramente encontrada ao sul (48 $44^{\prime}$ S) por Balech (1988).

\section{Dinophysis brevisulcus Tai \& Skogsberg (Figura 24)}

Células de tamanho pequeno a mediano, de epiteca baixa e arredondada. Aleta cingular anterior algo oblíqua dorsalmente. Aleta sulcal esquerda de largura quase uniforme na maior parte de sua extensão, terminando de forma arredondada, na ausência da terceira costela. Aleta sulcal direita somente chega até a segunda costela.

Tamanho: Comprimento da célula: 40-43 $\mu \mathrm{m}$; Largura da Epiteca: 12-13 $\mu \mathrm{m}$; Largura da Hipoteca: 37-38 $\mu \mathrm{m}$.

Distribuição: Foi encontrada na plataforma continental de AC (1 ind.) e CSMG (1 ind.) no período de inverno de 2005, sob influência de Água Subtropical de Plataforma. Espécie rara no Oceano Atlântico Sudoeste encontrada em águas da Corrente do Brasil entre $37^{\circ} \mathrm{S}$ e $38^{\circ} 45^{\prime} \mathrm{S}$ (Balech 1988).

\section{Dinophysis caudata Saville-Kent (Figura 27)}

Células grandes com um apêndice caudal definido. Aletas cingulares estriadas, às vezes irregularmente. Aleta sulcal esquerda grande e larga com costelas bem desenvolvidas.

Tamanho: Comprimento da célula: 59-92 $\mu \mathrm{m}$; Largura da Epiteca: 15-28 $\mu \mathrm{m}$; Largura da Hipoteca: 28-49 $\mu \mathrm{m}$.

Distribuição: Espécie com ampla distribuição e abundância mais expressiva durante o período de inverno (AC 299 ind.; CSMG 356 ind.). No cruzeiro de verão, ocorreu exclusivamente em AC, na região costeira e de plataforma continental (21 indivíduos). No Oceano Atlântico Sudoeste, abundante em águas neríticas e oceânicas até o limite austral de $43^{\circ} 33^{\prime} \mathrm{S}$, apresentando grande tolerância à variação de salinidade e de temperatura (Balech 1988). Em águas oceânicas da Região Central do Brasil, poucos exemplares foram encontrados desde a latitude de $13^{\circ} \mathrm{S}$ até $22^{\circ} 30^{\prime}$ S, próximo ao Cabo de S. Tomé (Tenenbaum 2006).

Produção de toxinas: Espécie produtora de toxinas diarréicas (DSP) do tipo AO, DTX2 e PTX2 (Fernández et al. 2006).

\section{Dinophysis caudata f. diegensis (Figura 19)}

Células de tamanho médio. Em vista lateral, a parte anterior da hipoteca, até aproximadamente a implantação da terceira costela, apresenta os lados quase retos e paralelos. Posteriormente, convergem em um triângulo caudal irregular, pontiagudo ou algo mais grosseiro. Epiteca muito achatada e inclinada dorso-ventralmente. Aleta cingular anterior oblíqua. Aleta sulcal esquerda bastante ampla. Recentemente foi comprovado que $D$. diegensis faz parte do ciclo de vida de D. caudata e deve ser considerada como D. caudata f. diegensis (Reguera et al. 2007).
Tamanho: Comprimento da célula: 49-61 $\mu$ m; Largura da Epiteca: 10-19; Largura da Hipoteca: 18-30 $\mu \mathrm{m}$.

Distribuição: Foi encontrada na plataforma continental e águas oceânicas em período de inverno em AC (7 indivíduos). No Oceano Atlântico Sudoeste, espécie rara, encontrada somente em águas do Sul do Brasil (Balech 1988).

\section{Dinophysis circumsutum (Karsten) Balech (Figura 34)}

\section{Sin.: Phalacroma circumsutum Karsten}

Célula grande e oval em vista lateral, de polo anterior achatado. Epiteca pouco elevada, levemente convexa, achatada e extensa no sentido dorso-ventral. Borda dorsal e ventral da hipoteca quase paralela em sua metade anterior. Aletas cingulares de largura média, um pouco oblíquas e praticamente lisas. Espinho posterior muito desenvolvido, que se implanta algo ventral e se inclina nesta direção. Aleta sulcal direita ampla, de borda livre convexa, terminando entre a segunda e terceira costelas. Aleta sulcal esquerda bem desenvolvida, especialmente junto da terceira costela, estendendo-se até o espinho posterior. As costelas são delgadas, a segunda está mais próxima da primeira do que da terceira. Espécie heterotrófica.

Tamanho: Comprimento da célula: $72 \mu \mathrm{m}$; Largura da Epiteca: $50 \mu \mathrm{m}$; Largura da Hipoteca: $56 \mu \mathrm{m}$; Comprimento do Espinho: $25 \mu \mathrm{m}$.

Distribuição: Um único indivíduo foi identificado na plataforma continental de AC no período de inverno, sob influência de Água Subtropical de Plataforma. Espécie termófila rara, com somente um exemplar encontrado no Oceano Atlântico Sudoeste ( $\left.37^{\circ} 17^{\prime} \mathrm{S}, 53^{\circ} 14^{\prime} \mathrm{W}\right)$ por Balech (1988).

\section{Dinophysis doryphora (Stein) Abé (Figura 35)}

\section{Sin.: Phalacroma doryphorum Stein}

Células de tamanho médio a grande. Em vista lateral apresenta forma oval, com epiteca elevada, convexa e algumas vezes achatada no centro. Cíngulo convexo com aletas cingulares lisas, quase horizontais. Um apêndice triangular largo e sem reforço central está implantado no pólo posterior, em seu lado ventral, mas com frequência se vê um espessamento em sua ponta e às vezes, algo reticulado. Aleta sulcal esquerda apresenta a segunda costela mais próxima da primeira do que da terceira. Esta última é grande, em geral fina, e às vezes claviforme. Aleta sulcal direita com a borda livre levemente sinuosa, terminando na terceira costela ou um pouco adiante. Espécie heterotrófica.

Tamanho: Comprimento da célula: 52-73 $\mu \mathrm{m}$; Largura da Epiteca: $32-51 \mu \mathrm{m}$; Largura da Hipoteca: $44-63 \mu \mathrm{m}$; Comprimento do Espinho: 8-15 $\mu \mathrm{m}$.

Distribuição: Foi encontrada em águas neríticas e oceânicas nos períodos de inverno (AC 1 ind.; CSMG 4 ind.) e verão (AC 2 ind.; CSMG 5 ind.). Espécie termófila, abundante em algumas estações da Corrente do Brasil no Oceano Atlântico Sudoeste, ao Norte de $39^{\circ} \mathrm{S}$ (Balech 1988). Em águas oceânicas da Região Central do Brasil, encontrada desde a latitude de $13^{\circ} 30^{\prime} \mathrm{S}$ até $20^{\circ} 40^{\prime} \mathrm{S}$, na cadeia das ilhas oceânicas de Vitória-Trindade (Tenenbaum 2006).

\section{Dinophysis dubia Balech (Figura 16)}

Células de tamanho pequeno a médio, de formato oval assimétrico com o polo posterior maior e notadamente arredondado. Epiteca muito pequena e baixa. Membranas cingulares e sulcais esculpidas irregularmente. Borda dorsal do cíngulo côncava e quase horizontal. Aleta sulcal esquerda bem desenvolvida, de largura quase homogênea e borda livre irregularmente convexa. A terceira costela é geralmente curvada 
Dinophysiales no Sul do Brasil
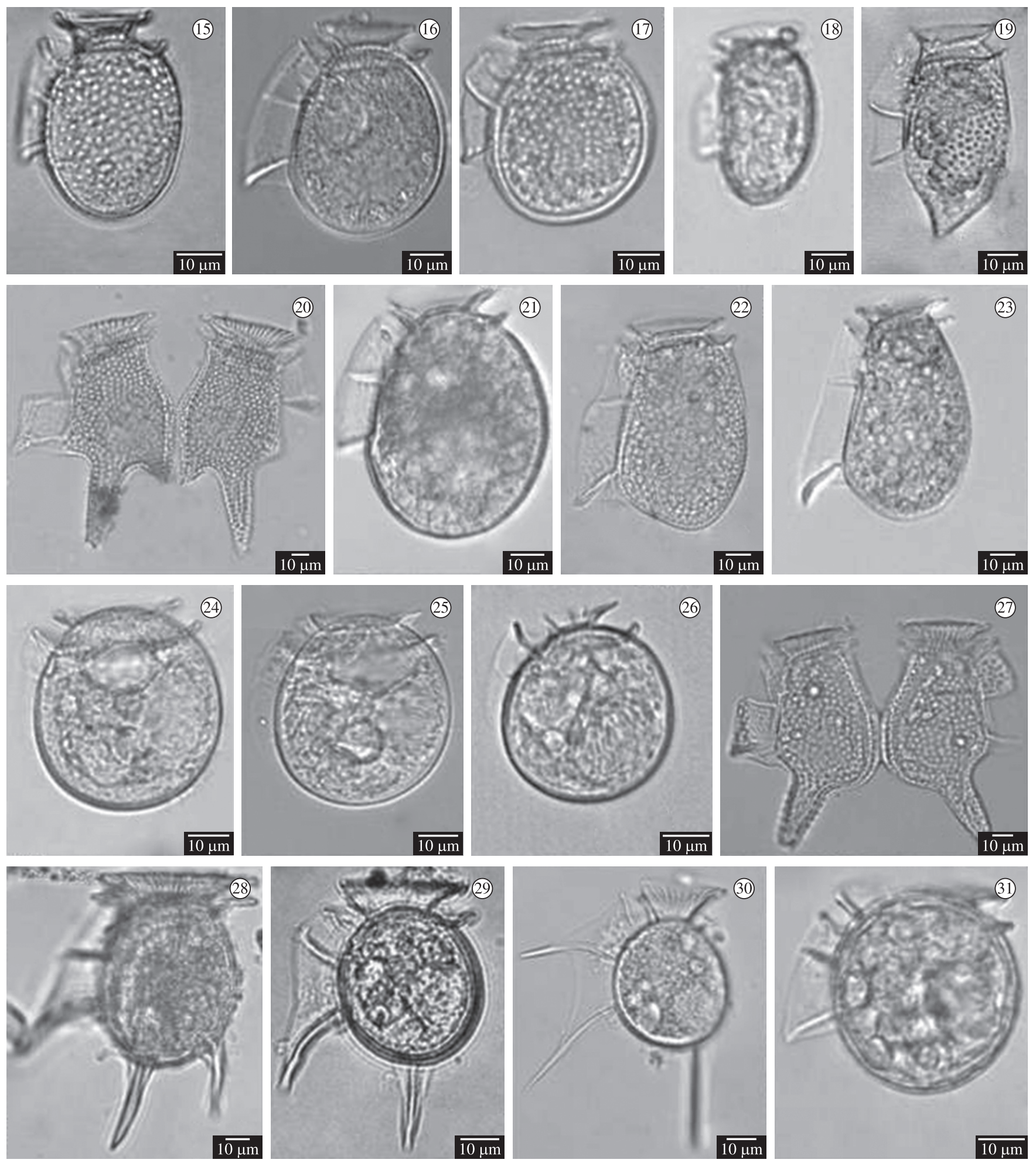

Figuras 15-31. 15) Dinophysis acuminata; 16) D. dubia; 17) D. punctata; 18) D. microstrigilisformis; 19) D.caudata f. diegensis; 20) D. tripos; 21) D. fortii; 22) D. schroederi (morfotipo Inverno 2005); 23) D. schroederi (morfotipo verão 2007); 24) D. brevisulcus; 25) D. similis; 26) D. bibulbus; 27) D. caudata; 28) D. nias; 29) D.pusilla; 30) D. schuetti; 31) D. exigua.

para trás e às vezes, um pouco mais grossa em seu extremo. Aleta sulcal direita curta. $\mathrm{O}$ nome 'dubia' reflete uma certa incerteza quanto a identificação desta espécie, por certa semelhança com D. acuminata Claparède \& Lachmann e D. sphaerica Jörgensen.
Tamanho: Comprimento da célula: 44-46 $\mu \mathrm{m}$; Largura da Epiteca: 9-14 $\mu \mathrm{m}$; Largura da Hipoteca: 34-36 $\mu \mathrm{m}$.

Distribuição: Foi encontrada na plataforma continental em CSMG em período de verão (2 ind.) e em águas oceânicas no inverno (1 ind.) sob a influência de Água Tropical e Água 
Subtropical de Plataforma em ambos os períodos. No Oceano Atlântico Sudoeste, encontrada com certa abundância em duas estações $\left(43^{\circ} 58^{\prime} \mathrm{S}, 59^{\circ} 13^{\prime} \mathrm{W}\right.$ e $\left.47^{\circ} 45^{\prime} \mathrm{S}, 55^{\circ} 58^{\prime} \mathrm{W}\right)$ por Balech (1988).

\section{Dinophysis exigua Koifoid \& Skogsberg (Figura 31)}

Células pequenas, quase isodiamétricas em vista lateral, podendo ser um pouco mais altas ou largas. Região posterior arredondada. Epiteca baixa, regularmente convexa e geralmente encoberta pela borda livre da aleta cingular anterior. Membranas cingulares lisas e oblíquas. Aleta sulcal esquerda relativamente grande e larga no nível da terceira costela, onde forma um ângulo quase reto. Aleta sulcal direita alcança a terceira costela.

Tamanho: Comprimento da célula: 28-37 $\mu \mathrm{m}$; Largura da Epiteca:13-20 $\mu \mathrm{m}$; Largura da Hipoteca: 23-34 $\mu \mathrm{m}$.

Distribuição: Foi encontrada na plataforma continental e em águas oceânicas no período de verão no CSMG (43 ind.) e $\mathrm{AC}$ (3 ind.) e somente em águas oceânicas no inverno em AC (1 ind.). A distribuição parece ser influenciada pela presença de Águas Tropicais. No Oceano Atlântico Sudoeste, espécie rara na Corrente do Brasil entre $37^{\circ} 17^{\prime} \mathrm{S}$ e $39^{\circ}$ 02' S (Balech 1988). Em águas oceânicas da Região Central do Brasil, encontrada desde a latitude de $13^{\circ} \mathrm{S}$ até $21^{\circ} 30^{\prime} \mathrm{S}$, e na cadeia de ilhas oceânicas de Vitória-Trindade (Tenenbaum 2006).

\section{Dinophysis fortii Pavillard (Figura 21)}

\section{Sin.: Dinophysis intermedia Pavillard}

Células de tamanho médio, de forma elíptica oval em vista lateral. Epiteca achatada. Hipoteca com a borda ventral quase reta e a borda dorsal convexa, com o extremo posterior arredondado. O eixo longitudinal é claramente inclinado ventralmente. Aleta sulcal esquerda grande e de largura pouco variável, frequentemente esculpida.

Tamanho: Comprimento da célula: 49-61 $\mu \mathrm{m}$; Largura da Epiteca: 11-20 $\mu \mathrm{m}$; Largura da Hipoteca: 34-46 $\mu \mathrm{m}$. O tamanho desta espécie variou localmente, os exemplares da região têm uma faixa de tamanho menor do que a dos indivíduos encontrados no Mar Mediterrâneo.

Distribuição: Foi encontrada em águas costeiras, na plataforma continental e região oceânica no período de inverno em CSMG (54 ind.). No verão, na plataforma continental de AC (3 ind.) e CSMG (10 ind.). No Oceano Atlântico Sudoeste, encontrada ao norte de $39^{\circ} \mathrm{S}$, associada a Corrente do Brasil (Balech 1988). Tavares et al. (2009) identificaram indivíduos dessa espécie em áreas de maricultura de SC, classificando-a juntamente com D. acuminata (Complexo D. acuminata).

Produção de toxinas: Espécie produtora de toxinas diarréicas do tipo DTX1, PTX2 e AO (Taylor et al. 2004).

\section{Dinophysis hastata Stein (Figura 32)}

Células de tamanho médio a grande, de forma oval muito larga e um pouco irregular, em vista lateral. Epiteca convexa, baixa e achatada no centro, não sobressaindo da aleta cingular anterior. Esta é provida de numerosas estrias. Na extremidade posterior da célula, arredondada ou algo mais aguda, está implantado um apêndice triangular espiniforme orientado ventralmente, o qual geralmente apresenta um reforço ou espinho central que começa por 2 raízes separadas. Aleta sulcal esquerda grande, com a terceira costela comprida e forte, às vezes muito engrossada. Aleta sulcal direta curta, chegando aproximadamente até a segunda costela. Ambas aletas sulcais são frequentemente esculpidas, com um retículo irregular.

Tamanho: Comprimento da célula: $65-74 \mu \mathrm{m}$; Largura da Epiteca: 24-40 $\mu \mathrm{m}$; Largura da Hipoteca: 57-66 $\mu \mathrm{m}$; Espinho: 19-26 $\mu \mathrm{m}$.
Distribuição: Foi encontrada na plataforma continental e região oceânica do $\mathrm{AC}$ no período do verão (2 ind.) e em águas oceânicas de CSMG no inverno (1 ind.). No Oceano Atlântico Sudoeste, espécie rara em águas oceânicas desde $32^{\circ}$ até $41^{\circ} 34^{\prime} \mathrm{S}$ (Balech 1988). Em águas oceânicas da Região Central do Brasil, encontrada frequentemente desde a latitude de $13^{\circ} \mathrm{S}$ até $24^{\circ} 30^{\prime} \mathrm{S}$, e presente em toda a cadeia de ilhas oceânicas de Vitória-Trindade (Tenenbaum 2006).

Produção de toxinas: Espécie suspeita como potencial produtora de toxinas diarréicas (Taylor et al. 2004).

\section{Dinophysis laevis Claparède \& Lachmann (Figura 43)}

Célula de tamanho pequeno, de forma mais ou menos elíptica e larga em vista lateral. Epiteca alta e arredondada. Aletas cingulares estreitas e lisas. Aleta sulcal esquerda estreita, sobretudo em sua parte final, alcançando mais ou menos o comprimento de $2 / 3$ da hipoteca. Terceira costela curta. Aleta sulcal direita termina aproximadamente entre a segunda e a terceira costela. Para alguns autores seria uma variedade de $D$. rotundata, merecendo estudo mais detalhado. Espécie heterotrófica.

Tamanho: Comprimento da célula: 35-40 $\mu \mathrm{m}$; Largura da Epiteca: 26-28 $\mu \mathrm{m}$; Largura da Hipoteca: 29-31 $\mu \mathrm{m}$.

Distribuição: Somente um indivíduo foi encontrado no período de inverno, na plataforma continental de CSMG. Espécie escassa no Oceano Atlântico Sudoeste desde a Antártica até $40^{\circ} 43^{\prime} \mathrm{S}$ (Balech 1988).

\section{Dinophysis microstrigilisformis Abé (Figura 18)}

Célula pequena, de forma comprida e estreita em vista lateral. A aleta sulcal esquerda é grande e estende-se ao longo de toda a borda ventral. Tanto esta aleta quanto as cingulares, apresentam-se lisas. As costelas são muito finas, a primeira sendo grande e oblíqua para cima. A terceira costela é pequena, menor do que a segunda. Espécie que possivelmente faz parte do ciclo de vida de D. fortii (Reguera 2003).

Tamanho: Comprimento da célula: $37 \mu \mathrm{m}$; Largura da Epiteca: $11 \mu \mathrm{m}$; Largura da Hipoteca: $24 \mu \mathrm{m}$.

Distribuição: Somente um indivíduo foi encontrado no período de inverno na plataforma continental de AC. No Oceano Atlântico Sudoeste, espécie encontrada somente em $37^{\circ} 32^{\prime} \mathrm{S}$ e $54^{\circ} 08^{\prime} \mathrm{W}$ por Balech (1988).

\section{Dinophysis minuta (Cleve) Balech (Figura 36)}

Sin.: Phalacroma minutum Cleve, Phalacroma elongatum Jörgensen, Dinophysis elongatum (Jörgensen) Abé

Célula de tamanho médio, estreita, de formato anguloso em vista lateral. Epiteca alta e arredondada. Hipoteca quase sempre assimétrica, com a borda dorsal regularmente convexa, borda ventral reta e praticamente perpendicular ao cíngulo em sua parte anterior. Aleta sulcal esquerda longa e estreita, somente mais larga entre a primeira e a segunda costela. Esta se situa mais próxima da terceira do que da primeira costela. A terceira costela é curta, e a borda livre entre as duas últimas costelas é um pouco côncava. Aleta sulcal direita grande, estendendo-se quase até a terceira costela. Aletas cingulares horizontais e estreitas. Espécie heterotrófica.

Tamanho: Comprimento da célula: $55 \mu \mathrm{m}$; Largura da Epiteca: $30 \mu \mathrm{m}$; Largura da Hipoteca: $33 \mu \mathrm{m}$.

Distribuição: Somente um indivíduo foi encontrado no período de inverno, na plataforma continental em AC. Considerada por Balech (1988) uma espécie eurioica, encontrada desde as Ilhas Georgias ao sul até águas quentes do hemisfério Norte. Este autor ressaltou sua maior abundância em $38^{\circ} 25^{\prime} \mathrm{S}$, longe da costa. 
Dinophysis mitra Schütt (Figura 41)

\section{Sin.: Phalacroma mitra Schütt}

Células relativamente grandes, com a borda dorsal da hipoteca convexa e a parte posterior ventral côncava, em vista lateral. Epiteca baixa, sobressaindo levemente da aleta cingular anterior, a qual se apresenta horizontal, com numerosas estrias. Aleta sulcal esquerda grande, estendendo-se por toda a borda ventral em sua parte anterior e reta. As três costelas são relativamente equidistantes em suas bases, mas a terceira é mais longa. Aleta sulcal direita atinge a terceira costela. Espécie heterotrófica. Existe dúvida sobre a validade desta espécie, pela sua semelhança morfológica com D. rapa, mas de menor tamanho (Balech 1988).

Tamanho: Comprimento da célula: 44-65 $\mu \mathrm{m}$; Largura da Epiteca: 23-40 $\mu \mathrm{m}$; Largura da Hipoteca: 33-54 $\mu \mathrm{m}$. O tamanho
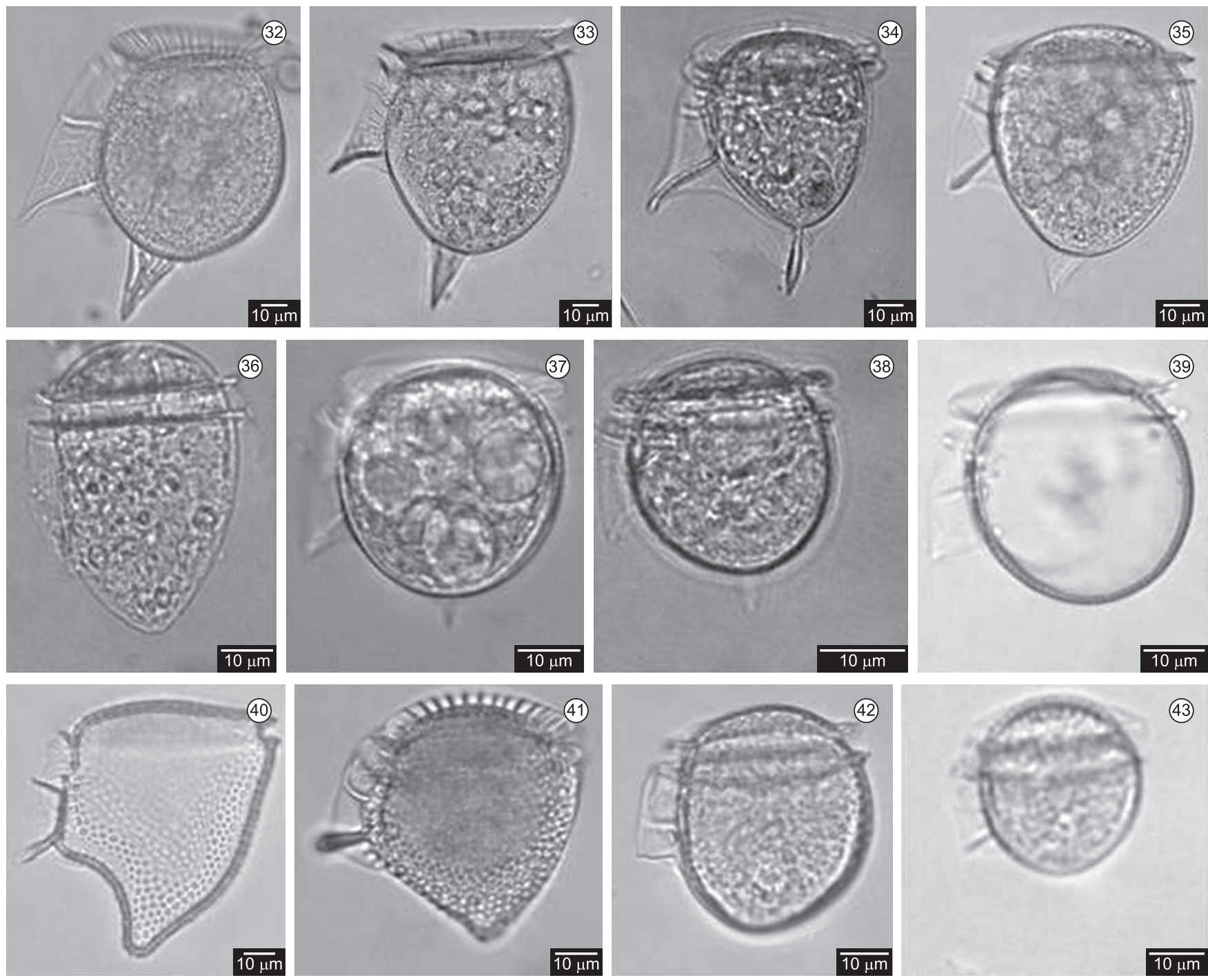

(43)
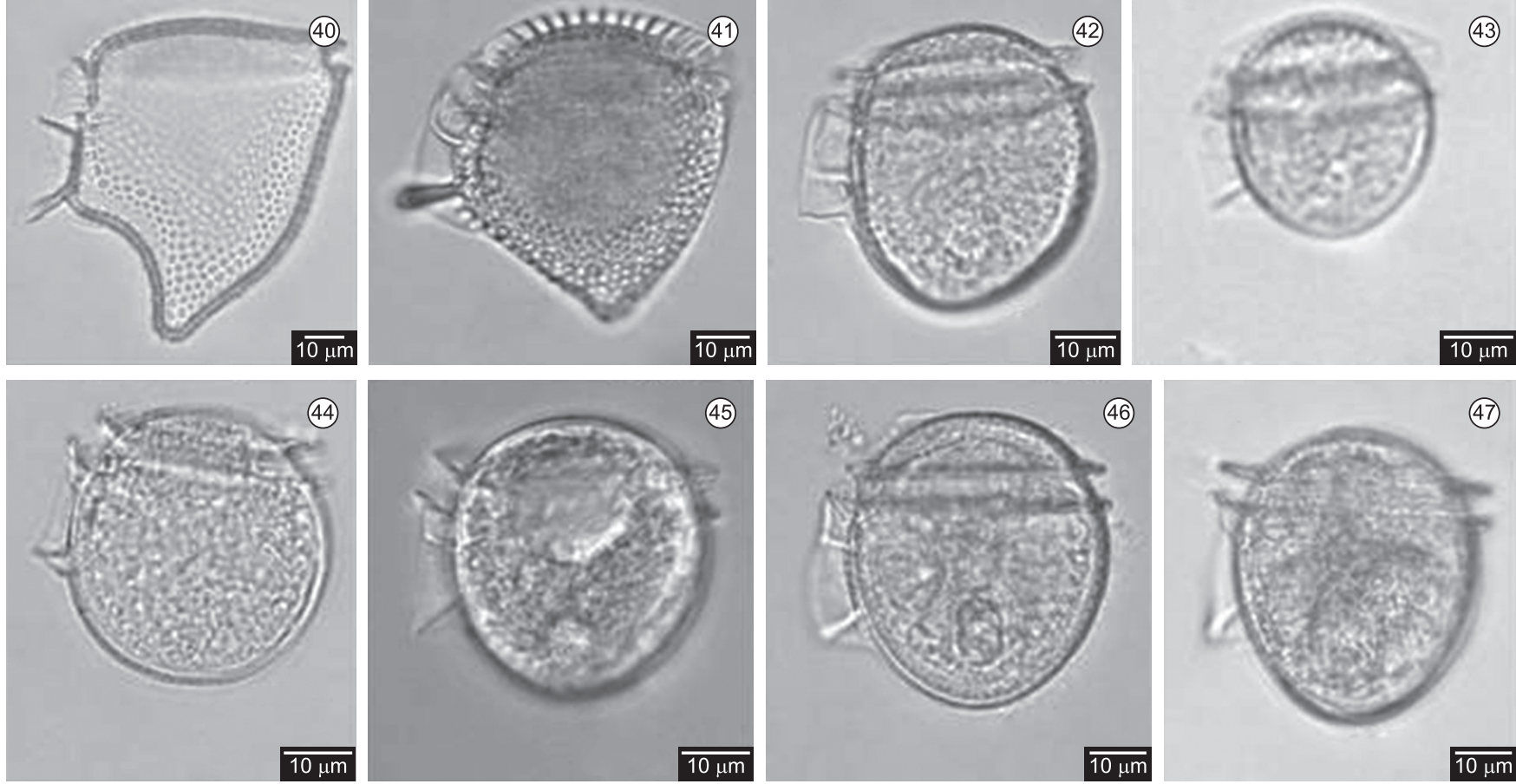

Figuras 32-47.32) Dinophysis hastata;33) D. odiosa; 34) D. circumsutum; 35) D. doryphora; 36) D. minuta; 37) D. ovata; 38) D. mucronata; 39) D. amphora; 40) D. rapa; 41) D. mitra; 42) D. scrobiculata; 43) D. laevis; 44) D. rotundata; 45) D. parvula; 46) D. operculoides; 47) D. amandula. 
dos exemplares encontrados são ligeiramente menores do que os descritos por Balech (1988).

Distribuição: Foi encontrada em maior número durante o período de verão, na plataforma continental e região oceânica de AC (11 ind.) e CSMG (8 ind.), mas também no inverno, na plataforma continental de CSMG (1 ind.). Espécie termófila considerada oceânica por Balech (1988), que a encontrou ao norte de $33^{\circ} 38^{\prime} \mathrm{S}$.

Produção de toxinas: Espécie produtora de toxinas diarréicas (DSP) DTX1 (Taylor et al. 2004).

Dinophysis mucronata (Kofoid \& Skogsberg) Sournia (Figura 38)

Sin.: Dinophysis paulseni (Schiller) Balech, Phalacroma paulseni Schiller, Phalacroma mucronatum Kofoid \& Skogsberg

Células de tamanho pequeno, de forma elíptica, larga em vista lateral. A epiteca, regularmente convexa, sobressai da aleta cingular anterior. As aletas cingulares são lisas e praticamente horizontais. A aleta sulcal esquerda apresenta uma borda livre quase reta, podendo ser convexa no nível da terceira costela. A sulcal direita termina um pouco antes da terceira costela. Espinho antapical localizado ventralmente.

Tamanho: Comprimento da célula: 32-35 $\mu \mathrm{m}$; Largura da Epiteca: 20-25 $\mu \mathrm{m}$; Largura da Hipoteca: 30-33 $\mu \mathrm{m}$; Comprimento do Espinho: 5-7 $\mu \mathrm{m}$.

Distribuição: Foi encontrada somente no período de inverno, na plataforma continental e águas oceânicas de AC (6 ind.), sob a influência de Água Costeira e Água Subtropical de Plataforma. Espécie de ampla distribuição geográfica, mas pouco representada no Oceano Atlântico Sudoeste (Balech 1988).

\section{Dinophysis nias Karsten (Figura 28)}

Células de tamanho médio, de forma oval-trapézica em vista lateral. Epiteca um pouco elevada, convexa, mas ainda totalmente inserida na aleta cingular anterior, que é estriada. Aleta cingular posterior bem desenvolvida, e cíngulo convexo. Hipoteca algo pentagonal com extremo posterior um pouco acuminado, no qual se insere um espinho grande, robusto e circundado por membranas estreitas. $\mathrm{Na}$ base da borda dorsal, existe outro espinho parecido, mais côncavo ventralmente e sustentado por duas ou três raízes. Aleta sulcal esquerda grande, com a borda livre reta ou ligeiramente ondulada. As duas primeiras costelas são delgadas mas a terceira é robusta e grande, curvada para trás. A segunda costela é um pouco mais delgada, reta ou curvada para frente. Aleta sulcal direita bem menor, estendendo-se um pouco além da segunda costela, com borda livre convexa.

Tamanho: Comprimento da célula: 58-60 $\mu \mathrm{m}$; Largura da Epiteca: 15-23 $\mu$ m; Largura da Hipoteca: 43-48 $\mu \mathrm{m}$; Comprimento dos espinhos: dorsal: 24-26 $\mu \mathrm{m}$, e ventral: $27-30 \mu \mathrm{m}$.

Distribuição: Foi encontrada somente no período de inverno, na plataforma continental de CSMG (1 ind.) e região oceânica de AC (1 ind.), sob influência de Água Tropical e Água Subtropical de Plataforma. No Oceano Atlântico Sudoeste, encontrada raramente ao norte de $37^{\circ} 17^{\prime} \mathrm{S}$ e considerada oceânica de águas quentes (Balech 1988).

\section{Dinophysis odiosa (Pavillard) Tai \& Skogsberg (Figura 33)}

Células de tamanho médio a grande, de forma oval muito larga, levemente irregular em vista lateral. Epiteca um pouco achatada no centro e ligeiramente saliente, mas não sobressaindo da aleta cingular anterior, a qual é provida de numerosas estrias. $\mathrm{Na}$ extremidade posterior arredondada, se implanta um apêndice triangular espiniforme, em geral na porção mais ventral. Aleta sulcal esquerda grande, bem como a terceira costela que é forte e, às vezes, bem grossa. Aleta sulcal direita pode passar da segunda costela. Ambas as aletas sulcais são frequentemente esculpidas, com um retículo irregular. Morfologicamente, a espécie é muito semelhante a $D$. hastata, diferindo principalmente na altura da epiteca.

Tamanho: Comprimento da célula: 74-77 $\mu \mathrm{m}$; Largura da Epiteca: 43-46 $\mu \mathrm{m}$; Largura da Hipoteca: $66 \mu \mathrm{m}$; Comprimento do Espinho: 14-23 $\mu \mathrm{m}$.

Distribuição: Foi encontrada na plataforma continental nos períodos de inverno em CSMG ( 1 ind.) e de verão em AC ( 1 ind.). Em águas oceânicas da Região Central do Brasil, encontrada em três estações entre a latitude de $13^{\circ} \mathrm{S}$ e $20^{\circ} 30^{\prime} \mathrm{S}$, nas ilhas oceânicas Vitória-Trindade (Tenenbaum 2006).

Dinophysis operculoides (Schütt) Balech (Figura 45)

\section{Sin.: Phalacroma operculoides Schütt}

Células de tamanho médio, de forma elíptica em vista lateral. Epiteca regularmente convexa e bastante saliente. Hipoteca de extremo posterior arredondado. Aletas cingulares horizontais, estreitas e aparentemente lisas, podendo apresentar um reticulado muito débil. Cíngulo segue mais ou menos o contorno da hipoteca. Aleta sulcal esquerda mais larga a partir da segunda costela, que está mais próxima da primeira do que da terceira. As três costelas são quase sempre delgadas. A segunda delas, tem um reforço em forma de "V", muito aberto para fora. A essa altura a aleta se estreita. Aleta sulcal direita é grande e marcadamente redonda entre a segunda e a terceira costela. Espécie heterotrófica.

Tamanho: Comprimento da célula: 41-51 $\mu \mathrm{m}$; Largura da Epiteca: 23-37 $\mu \mathrm{m}$; Largura da Hipoteca: 35-45 $\mu \mathrm{m}$. Os tamanhos observados foram menores do que aqueles descritos em Balech (1988).

Distribuição: Foi encontrada na plataforma continental e em águas oceânicas nos períodos de inverno e verão em AC (inverno 2 ind.; verão 4 ind.) e CSMG (inverno 6 ind.; verão 4 ind.). No Oceano Atlântico Sudoeste, espécie encontrada frequentemente em águas frias e quentes até $46^{\circ} 14^{\prime} \mathrm{S}$ (Balech 1988).

Dinophysis ovata Claparède \& Lachmann (Figura 37)

Sin.: Phalacroma ovatum (Laparède \& Lachmann) Jörgensen

Células de tamanho pequeno, de forma larga e oval, em vista lateral. Epiteca moderadamente elevada, um pouco achatada no centro. O cíngulo acompanha o contorno da hipoteca. $\mathrm{Na}$ região antapical, regularmente arredondada, está implantado um apêndice espiniforme membranoso, hialino, um pouco irregular, podendo apresentar um estreitamento brusco em sua meia altura. Este apêndice não possui reforço interno e pode facilmente passar desapercebido. Aletas cingulares sub-horizontais, lisas e pouco desenvolvidas. Aleta sulcal esquerda de tamanho médio, regularmente expandida para trás, de borda livre convexa. Costelas delgadas, a segunda podendo ser muito tênue, mais próxima da primeira do que da terceira. Aleta sulcal direita termina um pouco antes da terceira costela. Quando o processo hialino é muito tênue, pode ser confundida com $D$. mucronata e exemplares pequenos de $D$. operculoides.

Tamanho: Comprimento da célula: 31-41 $\mu \mathrm{m}$; Largura da Epiteca:17-25 $\mu$ m; Largura da Hipoteca: 27-36 $\mu \mathrm{m}$; Comprimento do Espinho: 1-7 $\mu \mathrm{m}$.

Distribuição: Esteve amplamente distribuída mas somente em CSMG no período de verão (60 ind.). No inverno, foi encontrada em águas de plataforma continental e oceânicas de $\mathrm{AC}$ (23 ind.) e restrita a plataforma continental em CSMG (1 ind.). No Oceano 
Atlântico Sudoeste, encontrada em águas quentes oceânicas, entre $37^{\circ} 53^{\prime} \mathrm{S}$ e $39^{\circ} 02^{\prime} \mathrm{S}$ (Balech 1988).

\section{Dinophysis parvula (Schütt) Balech (Figura 45)}

Sin.: Phalacroma parvulum (Schütt) Jörgensen, Phalacroma prodictyum Stein var. parvula Schütt

Células de tamanho pequeno e, em vista lateral, de forma elíptica ou oval. Os dois pólos são um pouco diferentes, o posterior é arredondado e às vezes um pouco mais agudo do que o anterior. Epiteca regularmente arredondada, sobressaindo da aleta anterior. Contorno do cíngulo segue a curvatura da hipoteca. Membranas cingulares horizontais e lisas. Aleta sulcal esquerda mais curta do que a hipoteca, com costelas finas, que aumentam de comprimento da primeira à terceira. Borda livre um pouco convexa, e levemente angulosa na altura da segunda costela. Aleta sulcal direita termina entre a segunda e terceira costela. Espécie heterotrófica. Alguns autores acreditam que $D$. parvula faça parte do ciclo de vida de D. rotundata (Reguera 2003).

Tamanho: Comprimento da célula: 33-42 $\mu \mathrm{m}$; Largura da Epiteca: 20-33 $\mu \mathrm{m}$; Largura da Hipoteca: 29-40 $\mu \mathrm{m}$.

Distribuição: Foi encontrada no inverno em águas de plataforma continental e oceânicas em AC (5 ind.) e na plataforma continental em CSMG (2 ind.). No verão, foi observada em CSMG em águas de plataforma e oceânicas (36 ind.) e em AC, exclusivamente em águas oceânicas (5 ind.). No Oceano Atlântico Sudoeste, espécie considerada de águas frias, encontrada somente ao sul de $38^{\circ} \mathrm{S}$ (Balech 1988).

\section{Dinophysis punctata Jörgensen (Figura 17)}

Células de tamanho pequeno, de forma elíptica quase subcircular, e de extremo posterior arredondado. Epiteca pequena e achatada. Aleta cingular anterior desenvolvida, e a cingular posterior muito reduzida na região dorsal. Borda cingular dorsal inclinada. Aleta sulcal esquerda angulosa entre a segunda e terceira costelas. Aleta sulcal direita alcança somente a segunda costela, com a parte anterior levemente côncava e a posterior, reta.

Tamanho: Comprimento da célula: 32-35 $\mu \mathrm{m}$; Largura da Epiteca: $9 \mu \mathrm{m}$; Largura da Hipoteca: 26-30 $\mu \mathrm{m}$.

Distribuição: Foi encontrada na plataforma continental no período de verão em CSMG (2 ind.). No Oceano Atlântico Sudoeste, somente um exemplar encontrado em $38^{\circ} 27^{\prime} \mathrm{S}$ e $53^{\circ} 06^{\prime} \mathrm{W}$, em águas quentes $\left(15,6^{\circ} \mathrm{C}\right)$ e de alta salinidade $(35,73)$ (Balech 1988)

\section{Dinophysis pusilla Jörgensen (Figura 29)}

Células pequenas de forma elíptica em vista lateral, ou levemente oval na extremidade anterior. Epiteca convexa e reduzida. Extremo posterior arredondado em cujo centro se implanta um apêndice caudal estreito e longo, triangular e pontiagudo, formado por um espinho central e membrana na borda. Aleta cingular anterior grande, sem estrias, podendo apresentar reforços tênues, irregulares e incompletos. Aleta sulcal esquerda larga, apresentando a segunda costela bem desenvolvida, oblíqua e côncava para a parte anterior. Terceira costela grande, forte, oblíqua e côncava para trás. Aleta sulcal direita curta e pouco visível.

Tamanho: Comprimento da célula: 28-34 $\mu \mathrm{m}$; Largura da Epiteca:7-14 $\mu \mathrm{m}$; Largura da Hipoteca: 25-30 $\mu \mathrm{m}$; Comprimento do Espinho:14-23 $\mu \mathrm{m}$.

Distribuição: No inverno, foi encontrada na plataforma continental de AC (2 ind.) e em águas oceânicas de CSMG (1 ind.); no verão, somente em CSMG, em águas costeiras e de plataforma (2 ind.). Espécie considerada termófila e oceânica, no Oceano Atlântico Sudoeste foi encontrado somente um exemplar na Corrente do Brasil, em $38^{\circ} 56^{\prime} \mathrm{S}$ e $53^{\circ} 28^{\prime} \mathrm{W}$ (Balech 1988).

\section{Dinophysis rapa Stein (Figura 40)}

\section{Sin.: Phalacroma rapa Stein}

Célula grande, de forma trapezoidal em vista lateral, com a borda posterior-ventral bastante extensa e côncava. Borda dorsal da hipoteca suavemente convexa. Epiteca baixa, mas sobressaindo da aleta cingular anterior, a qual é horizontal e apresenta numerosas estrias. A aleta sulcal esquerda recobre toda a parte reta da borda ventral. A aleta sulcal direita alcança a terceira e maior costela. Espécie heterotrófica.

Tamanho: Comprimento da célula: 78 m; Largura da Epiteca: $54 \mu \mathrm{m}$; Largura da Hipoteca: $58 \mu \mathrm{m}$. Distribuição: Um único indivíduo foi encontrado no período de verão, em águas oceânicas de CSMG. No Oceano Atlântico Sudoeste, espécie de águas oceânicas quentes, encontrada na Corrente do Brasil, ao Norte de $39^{\circ} \mathrm{S}$ (Balech 1988). Em águas oceânicas da Região Central do Brasil, encontrada em $21^{\circ}$ a $22^{\circ} \mathrm{S}$, próximo ao Cabo de $\mathrm{S}$. Tomé (Tenenbaum 2006).

\section{Dinophysis rotundata Claparède \& Lachmann (Figura 44)}

Sin.: Phalacroma rotundatum (Claparède \& Lachmann) Kofoid \& Michener

Células de tamanho médio, em vista lateral de forma elíptica, muito largas e algo assimétricas, quase subcirculares. Epiteca convexa, pouco elevada e geralmente um pouco achatada no centro. Aleta cingular anterior lisa e praticamente horizontal. Aleta sulcal esquerda desenvolvida e, em sua margem livre, algo convexa. Aleta sulcal direita ondulada, alcançando a terceira costela. Espécie heterotrófica.

Tamanho: Comprimento da célula: $40 \mu \mathrm{m}$; Largura da Epiteca: $23 \mu \mathrm{m}$; Largura da Hipoteca: $40 \mu \mathrm{m}$.

Distribuição: Foi encontrada na plataforma continental no período de inverno em AC (1 ind.) e CSMG (4 ind.). Espécie de águas frias, encontrada frequentemente no Oceano Atlântico Sudoeste desde a Convergência Antártica, até no máximo a latitude de $37^{\circ} 17^{\prime} \mathrm{S}$ por Balech (1988). Em águas oceânicas da Região Central do Brasil, encontrada frequentemente entre a latitude de $13^{\circ} \mathrm{S}$ e $24^{\circ} 30^{\prime} \mathrm{S}$, presente em toda a cadeia de ilhas oceânicas de Vitória-Trindade (Tenenbaum 2006).

Produção de toxinas: este foi o primeiro dinoflagelado heterotrófico com produção confirmada de toxinas diarréicas (DTX1) (Taylor et al. 2004).

\section{Dinophysis schroederi Pavillard (Figuras 22 e 23)}

Células grandes, com epiteca achatada e muito reduzida. Aletas cingulares lisas. A borda ventral é quase reta, e a dorsal convexa, mais curvada abaixo da metade da altura da hipoteca. Largura máxima se localiza na união dos $2 / 3$ anteriores com $1 / 3$ posterior. Extremidade antapical pode ser arredondada ou angulosa. Aleta sulcal esquerda longa, se estendendo até a parte postero-ventral. Aleta sulcal direita curta, geralmente até a segunda costela. A terceira costela é mais robusta e pode apresentar-se claviforme. Esta espécie apresenta uma grande variação morfológica na extremidade hipotecal posterior, sendo considerada morfológicamente intermediária em uma série que tem em seus extremos a forma subantartica $D$. truncata, e a forma boreal D. acuta (Balech 1988).

Tamanho: Comprimento da célula: 61-73 $\mu \mathrm{m}$; Largura da Epiteca: 10-24 $\mu \mathrm{m}$; Largura da Hipoteca: 32-48 $\mu \mathrm{m}$. Exemplares algo menores do que os descritos por Balech (1988). 
Distribuição: Foi encontrada em águas costeiras e oceânicas em CSMG no período de inverno (18 ind.); no verão, em águas de plataforma e oceânicas em AC (6 ind.) e em águas oceânicas em CSMG (1 ind.). No Oceano Atlântico Sudoeste, espécie encontrada na Corrente do Brasil até $41^{\circ} 45^{\prime} \mathrm{S}$ (Balech 1988).

Dinophysis schuetti Murray \& Whitting (Figura 30)

\section{Sin.: Dinophysis uracantha Schütt}

Células de tamanho pequeno a médio. Em vista lateral, o formato é oval e irregular, alargado atrás, às vezes anguloso. Epiteca pequena, baixa e convexa. No extremo dorsal posterior da hipoteca se implanta um grande espinho robusto, um pouco côncavo na região ventral. Cíngulo convexo. Membrana cingular anterior ampla e com estrias evidentes. Aleta sulcal esquerda ampla e característica, com as segunda e terceira costelas muito grandes e robustas.

Tamanho: Comprimento da célula: 34-48 $\mu \mathrm{m}$; Largura da Epiteca: 7-11 $\mu \mathrm{m}$; Largura da Hipoteca: 30-36 $\mu \mathrm{m}$; Comprimento do Espinho: 20-32 $\mu \mathrm{m}$.

Distribuição: Foi encontrada em águas oceânicas e de plataforma no inverno na região de CSMG (3 ind.) e no verão na de AC (2 ind.). Espécie termófila oceânica, encontrada no Oceano Atlântico Sudoeste ao Norte de $39^{\circ} \mathrm{S}$ (Balech 1988). Em águas oceânicas da Região Central do Brasil, encontrada frequentemente desde a latitude de $13^{\circ}$ até $23^{\circ} \mathrm{S}$, também presente na cadeia de ilhas oceânicas de Vitória-Trindade (Tenenbaum 2006).

\section{Dinophysis scrobiculata Balech (Figura 42)}

Células pequenas, elipsoidalmente largas de extremo posterior arredondado. Epiteca convexa, saliente. Aleta sulcal esquerda com a segunda costela mais próxima da terceira do que da primeira. Aleta sulcal direita grande, alcançando a terceira costela. Escultura forte de poróides, que conferem um aspecto escuro à teca. Espécie heterotrófica.

Tamanho: Comprimento da célula: 37-50 $\mu \mathrm{m}$; Largura da Epiteca: 22-31 $\mu \mathrm{m}$; Largura da Hipoteca: 29-41 $\mu \mathrm{m}$.

Distribuição: Foi encontrada na plataforma continental e na região oceânica em AC (3 ind.) e em CSMG (23 ind.) no período de inverno. No verão, ocorreu somente em AC, em águas costeiras e de plataforma (2 ind.). No Oceano Atlântico Sudoeste, espécie frequentemente encontrada desde $36^{\circ} 28^{\prime} \mathrm{S}$ até a região Antártica, sendo classificada de águas frias (Balech 1988).

Dinophysis similis Kofoid \& Skogsberg (Figura 25)

\section{Sin.: Dinophysis taii Balech}

Células de tamanho médio. Em vista lateral, se apresentam ovais, assimétricas e com o eixo longitudinal inclinado para a direção ventral; extremidade posterior arredondada. Epiteca baixa, aleta cingular anterior muito alta e com estrias fortes. Aleta sulcal direita não apresenta a terceira costela, e sua borda posterior pode ser mais refringente.

Tamanho: Comprimento da célula: 31-39 $\mu \mathrm{m}$; Largura da Epiteca: 8-14 $\mu \mathrm{m}$; Largura da Hipoteca: 27-36 $\mu \mathrm{m}$. A espécie apresenta variações de tamanho, dependendo da região geográfica.

Distribuição: Encontrada somente no período de verão, em águas oceânicas de AC (1 ind.) e CSMG (1 ind.), associada com a influência de Água Tropical. No Oceano Atlântico Sudoeste, encontrada somente em $37^{\circ} 53^{\prime} \mathrm{S}, 53^{\circ} 58^{\prime} \mathrm{W}$ em águas quentes de alta salinidade (Balech 1988).

\section{Dinophysis tripos Gourret (Figura 20)}

Células grandes, com dois apêndices caudais característicos, o mais longo situado próximo da porção ventral e o mais curto na porção dorsal. Epiteca chata, inclinada, geralmente com uma concavidade central. Membrana cingular anterior estriada. Aleta sulcal esquerda muito ampla. Existem formas de transição entre $D$. tripos e $D$. caudata, mas em geral as duas espécies podem ser diferenciadas facilmente.

Tamanho: Comprimento da célula: 91-108 $\mu \mathrm{m}$; Largura da Epiteca: 23-32 $\mu \mathrm{m}$; Largura da Hipoteca: 41-53 $\mu \mathrm{m}$.

Distribuição: Os 118 indivíduos identificados foram encontrados no verão, em águas costeiras e de plataforma continental em CSMG, sob influência de água subtropical e tropical. No Oceano Atlântico Sudoeste, espécie considerada de águas frias embora não frequente entre $36^{\circ} 22^{\prime} \mathrm{S}$ e $55^{\circ} 50^{\prime} \mathrm{W}$ (Balech 1988), enquanto que Schiller classifica a espécie como termófila.

Produção de toxinas: Potencial produtor de toxina diarréica (DTX1) (Taylor et al. 2004).

\section{HISTIONEIS}

Histioneis cymbalaria Stein (Figura 2)

Sin.: Histioneis depressa Schiller

Em vista lateral, o corpo é largo e baixo, mais baixo no meio e mais alto próximo da parte dorsal. Os extremos do corpo são convexos, e a borda posterior é côncava no centro. Epiteca pequena e inclinada ventralmente e posteriormente. Borda cingular dorsal côncava, mas não inclinada. Membrana cingular anterior com um tubo alto e delgado, cuja parte distal é alargada e apresenta algumas estrias periféricas curtas e outras maiores ou ramificadas. Aleta cingular posterior alta, ligeiramente oblíqua no sentido antero-posterior e da região ventral para a dorsal, suavemente convexa. Borda ventral também regularmente convexa. Aleta sulcal esquerda grande, que se caracteriza por um reforço em forma de laço, de forma e altura variadas. Deste, geralmente forma-se outro laço menor, que pode prolongar-se em uma membrana triangular, com reticulado complexo e irregular. Espécie heterotrófica.

Tamanho: Comprimento total: $107 \mu \mathrm{m}$; Altura da Hipoteca: $16 \mu \mathrm{m}$; Largura da Hipoteca: $36 \mu \mathrm{m}$. Tamanho maior do que o descrito por Balech (1988).

Distribuição: Foi encontrada somente um indivíduo no período de verão na plataforma continental de CSMG. No Oceano Atlântico Sudoeste, espécie encontrada isoladamente em águas da Corrente do Brasil ao norte de $38^{\circ} 48^{\prime}$ S, sendo abundante em uma estação (Balech 1988).

Histioneis hyalina Kofoid \& Michener (Figura 3)

Células com a hipoteca reniforme. Aleta cingular anterior em forma de funil alongado e a aleta cingular posterior hialina. Aleta sulcal esquerda com as segunda e terceira costelas unidas, próximo a região central. Espécie heterotrófica.

Tamanho: Comprimento total: 61-67 $\mu \mathrm{m}$; Altura da Hipoteca: 15-17 $\mu \mathrm{m}$; Largura da Hipoteca: 21-24 $\mu \mathrm{m}$.

Distribuição: Foi encontrada somente no período de verão, em águas costeiras e de plataforma em CSMG (2 ind.) e oceânicas em AC (1 ind.). Em águas oceânicas da Região Central do Brasil, registrada entre $17^{\circ} \mathrm{S}$ e $24^{\circ} \mathrm{S}$ (Tenenbaum 2006) e ausente no Oceano Atlântico Sudoeste ao sul de $32^{\circ} \mathrm{S}$ no estudo de Balech (1988).

Histioneis megalocopa Stein (Figuras 6 e 7)

Sin.: Histioneis dolon Murray \& Whitting

Células grandes, com a hipoteca em forma de sela assimétrica e curvada. Aleta cingular anterior alta e com tubo comprido, o qual apresenta uma expansão apical com pequenos raios distais 
que se implantam sobre um reforço. Aleta cingular posterior alta, com um reforço sinuoso do qual saem esculturas irregulares que terminam em um segundo reforço, que sustenta pequenas estrias. A aleta sulcal esquerda é bem desenvolvida e prolongada para trás. A segunda e terceira costelas são oblíquas para trás e por baixo da última, a aleta forma um lóbulo semicircular com várias estrias concêntricas.

Tamanho: Comprimento total: 94-134 $\mu \mathrm{m}$; Altura da Hipoteca:

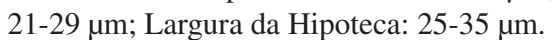

Distribuição: Foi encontrada em águas oceânicas no período de verão em CSMG (1 ind.) e AC (1 ind.), e no de inverno na plataforma continental e região oceânica de CSMG (2 ind.). Como $H$. dolon, esta espécie foi encontrada frequentemente em águas oceânicas próximas do Banco de Abrolhos $\left(19^{\circ} \mathrm{S}\right)$ e cadeia de ilhas oceânicas de Vitória-Trindade $\left(20^{\circ} 30^{\prime} \mathrm{S}\right)$ (Tenenbaum 2006), ao passo que no Oceano Atlântico Sudoeste, foram registrados somente dois exemplares ao norte de $37^{\circ} 17^{\prime} \mathrm{S}$ (Balech 1988).

\section{Histioneis milneri Murray \& Whitting (Figuras 13 e 14)}

\section{Sin.: Histioneis hippoperoides Kofoid \& Michener}

Célula grande, com o corpo no formato semelhante a uma sela, assimétrica e muito curvada. Membrana cingular anterior alta e com tubo comprido, cuja expansão apical é relativamente estreita. Membrana cingular posterior alta e estreita. A aleta sulcal esquerda é muito ampla. A segunda costela é oblíqua e curvada para baixo ou em forma de "S". A terceira costela segue a mesma tendência, mas sua porção distal é côncava para baixo. Esta aleta possui escultura irregular, podendo apresentar um reforço paralelo à borda livre, de onde partem pequenas estrias.

Tamanho: Comprimento total: $82 \mu \mathrm{m}$; Altura da Hipoteca: $22 \mu \mathrm{m}$; Largura da Hipoteca: $23 \mu \mathrm{m}$.

Distribuição: Foi encontrado somente um indivíduo no período de verão em águas oceânicas de AC. No Oceano Atlântico Sudoeste, a espécie é encontrada isoladamente na Corrente do Brasil ao norte de $37^{\circ} 20^{\prime} \mathrm{S}$ (Balech 1988). Em águas oceânicas da Região Central do Brasil, registrada como $H$. hippoperoides no Banco de Abrolhos, ilhas de oceânicas de Vitória-Trindade e em águas oceânicas próximo ao Cabo de S. Tomé, entre 17 e $22^{\circ} \mathrm{S}$ (Tenenbaum 2006).

\section{Histioneis para Murray \& Whitting (Figuras 4 e 5)}

Célula de forma triangular curvilínea em vista lateral, com o vértice posterior mais agudo. Epiteca ampla, muito inclinada, com uma ligeira saliência na parte média. Borda dorsal do cíngulo côncava, sobretudo no seu extremo anterior. Aleta cingular anterior ampla e com fortes e numerosas estrias em sua membrana. Aleta cingular posterior mais baixa, de diâmetro um pouco maior do que o da aleta cingular anterior, e com bordas dorsal e ventral em "S". Aleta sulcal esquerda grande e estreita. A terceira costela é forte, algo sinuosa e direcionada para a extremidade posterior. O seu comprimento é um pouco menor do que o corpo tecal, e apresenta escultura alveolar marcada. Espécie heterotrófica.

Tamanho: Comprimento total: $76 \mu \mathrm{m}$; Altura da Hipoteca: $28 \mu \mathrm{m}$; Largura da Hipoteca: $26 \mu \mathrm{m}$.

Distribuição: Foi encontrado somente um exemplar em águas oceânicas de $\mathrm{AC}$, no período de inverno. No Oceano Atlântico Sudoeste, encontrada na Corrente do Brasil até o limite austral de $37^{\circ} 20^{\prime} \mathrm{S}$ (Balech 1988). Em águas oceânicas da Região Central do Brasil, registrada próximo do Banco de Abrolhos e do Cabo de S. Tomé, entre $18^{\circ} \mathrm{S}$ e $21^{\circ} 30^{\prime} \mathrm{S}$ (Tenenbaum 2006).

\section{ORNITHOCERCUS}

\section{Ornithocercus heteroporus Kofoid (Figura 8)}

Células pequenas, de corpo elíptico um pouco alargado longitudinalmente. Epiteca muito pequena. Cíngulo não-escavado, às vezes retificado dorsalmente. Aleta sulcal esquerda se estende até a extremidade posterior, onde apresenta sua borda côncava e oblíqua à região ventral. Espécie heterotrófica.

Tamanho: Comprimento total: 65-69 $\mu \mathrm{m}$; Comprimento da célula: 29-30 $\mu \mathrm{m}$; Largura da Hipoteca: 26-28 $\mu \mathrm{m}$. Tamanho menor do que o descrito por Balech (1988).

Distribuição: Foi encontrada somente no período de verão em águas oceânicas da região do CSMG (2 ind.). Espécie termófila e oceânica, encontrada raramente no Oceano Atlântico Sudoeste em águas da Corrente do Brasil ao Norte de $37^{\circ} 20^{\prime} \mathrm{S}$ (Balech 1988). Em águas oceânicas da Região Central do Brasil, registrada desde a latitude de $13^{\circ} \mathrm{S}$ até $20^{\circ} 40^{\prime} \mathrm{S}$, na cadeia das ilhas oceânicas de Vitória-Trindade (Tenenbaum 2006).

\section{Ornithocercus magnificus Stein (Figura 11)}

Células grandes, em vista lateral com o corpo subcircular, praticamente isodiamétrico. O cíngulo na linha dorsal varia de ligeiramente convexo a algo côncavo. Epiteca reduzida, achatada ou um pouco convexa. $\mathrm{Na}$ aleta cingular anterior quase sempre se nota, além das estrias, outros segmentos curtos e, às vezes, um reticulado tênue, que pode cobrir toda a aleta. Teca ornamentada por pequenos alvéolos. Aleta sulcal esquerda com três lobos bem marcados: o do meio delimitado pelo extremo de duas costelas. As costelas estão unidas por um reforço que contorna a borda posterior. Das costelas podem partir alguns ramos mais ou menos curtos. Espécie heterotrófica.

Tamanho: Comprimento total: 84-108 $\mu \mathrm{m}$; Comprimento da célula: 34-44 $\mu \mathrm{m}$; Largura da Hipoteca: 38-44 $\mu \mathrm{m}$.

Distribuição: Foi encontrada em AC somente na região oceânica durante o verão (2 ind.) e em CSMG nos períodos de inverno na plataforma continental (11 ind.) e de verão na plataforma continental e região oceânica ( 8 ind.). No Oceano Atlântico Sudoeste, espécie abundante até o limite austral de $42^{\circ} 10^{\prime} \mathrm{S}$ (Balech 1988). Em águas oceânicas da Região Central do Brasil, foi a espécie de Ornithocercus mais frequente desde a latitude de $13^{\circ} 30^{\prime} \mathrm{S}$ até $20^{\circ} 40^{\prime} \mathrm{S}$, na cadeia das ilhas oceânicas de Vitória-Trindade (Tenenbaum 2006).

\section{Ornithocercus splendidus Schütt (Figura 10)}

As células são inconfundíveis pela presença de suas membranas cingulares muito amplas, com fortes e numerosas estrias que, com frequência, têm raiz dupla e a certa distância da base se ramificam, formando um reticulado irregular forte e complexo. A largura da hipoteca é maior do que o comprimento da célula, mas é difícil obter uma boa visualização lateral, devido à amplitude das aletas cingulares. Aleta sulcal esquerda com a borda posterior oblíqua, orientando-se para a região ventral. Entre os dois lóbulos formados por seus extremos, a aleta é côncava, podendo algumas vezes ser quase reta. O extremo dos lóbulos é mais ou menos pontiagudo e tem um reticulado de malha bem pequeno, complexo, que forma algumas manchas escuras.

Tamanho: Largura total (vista dorsal): 178-204 $\mu$; Altura da Hipoteca: 39-52 $\mu \mathrm{m}$; Largura da Hipoteca (vista dorsal): 26-34 $\mu \mathrm{m}$. Não foi possível obter as medidas com precisão devido à amplitude de suas aletas cingulares, que impediram a visão lateral.

Distribuição: Foi encontrada somente em águas oceânicas na região do CSMG nos períodos de inverno (1 ind.) e de verão (3 ind.). No Oceano Atlântico Sudoeste, registrada ao Norte de $43^{\circ} \mathrm{S}$ por Balech (1988). 


\section{Ornithocercus steinii Schütt (Figura 12)}

Célula de corpo subcircular grande, alterado pela epiteca chata e oblíqua, relativamente extensa. O cíngulo é muito assimétrico, muito mais alto dorsalmente, onde também é levemente côncavo. Aletas bem desenvolvidas, sendo a cingular posterior sustentada por numerosas estrias. A aleta cingular anterior tem raios em menor número e mais fortes, geralmente apresentando um reforço paralelo à margem. Aleta sulcal esquerda geralmente com quatro lóbulos posteriores pouco marcados, cada um deles delimitado por uma costela, com ramos curtos. Teca apresenta um alveolado grande. Espécie heterotrófica.

Tamanho: Comprimento total: 123-128 $\mu$ m; Comprimento da célula: 53-58 $\mu \mathrm{m}$; Largura da Hipoteca: 55-63 $\mu \mathrm{m}$.

Distribuição: Foi encontrada somente na plataforma continental na região do CSMG, no período de inverno (2 ind.). No Oceano Atlântico Sudoeste, após O. magnificus, esta é a segunda espécie mais abundante em águas da Corrente do Brasil, até o limite austral de $40^{\circ} 10^{\prime} \mathrm{S}$ (Balech 1988).

Ornithocercus thumii (Schmidt) Kofoid \& Skogsberg (Figura 9)

\section{Sin.: Parelion thumii Schmidt}

Células com epiteca ampla, chata e geralmente com extremo dorsal do cíngulo muito côncavo e erguido na parte anterior. As membranas cingulares e a aleta sulcal esquerda são ornamentadas, o lóbulo médio da aleta sulcal esquerda geralmente apresenta uma costela axial. A superfície da hipoteca apresenta alveolado facilmente visível. Espécie com certa semelhança a $O$. magnificus podendo haver exemplares de transição. Espécie heterotrófica.

Tamanho: Comprimento total: $137 \mu \mathrm{m}$; Comprimento da célula: $59 \mu \mathrm{m}$; Largura da Hipoteca: $63 \mu \mathrm{m}$.

Distribuição: Foi encontrada somente em águas oceânicas no período de inverno em CSMG (2 ind.). No Oceano Atlântico Sudoeste, associada com águas tropicais da Corrente do Brasil ao Norte de $37^{\circ} \mathrm{S}$ (Balech 1988).

\section{Distribuição espacial e temporal das espécies de Dinophysiales}

No total foram identificadas 43 espécies de Dinophysiales, das quais 33 e 30 foram encontradas em amostras coletadas no inverno de 2005 e verão de 2007, respectivamente (Tabela 1). Algumas espécies apresentaram ampla distribuição na área costeira, de plataforma continental e oceânica, como D. acuminata, D. caudata, D. fortii e D. schroederi no inverno de 2005 e Dinophysis acuminata, D. exigua, D. ovata e Histioneis hyalina no verão de 2007. Por outro lado, algumas espécies apresentaram distribuição restrita à região oceânica, sob influência da Corrente do Brasil, como observado para Dinophysis dubia, D. exigua, D. schuetti, Histioneis para, Ornithocercus thumii e O. splendidus no inverno de 2005, e para D. similis, D. rapa, H. megalocopa, H. milneri, O. heteroporus e O. splendidus no verão de 2007.

\section{Discussão}

Tomando-se como base o Atlas de Dinoflagelados del Atlantico Sudoccidental (Balech 1988) no qual foram registradas 11 espécies de Amphisolenia, 49 de Dinophysis, 13 de Histioneis e sete de Ornithocercus, e comparando-se com o número de espécies encontradas no Sul do Brasil no presente estudo (Amphisolenia 1; Dinophysis 32; Histioneis 5; Ornithocercus 5), observa-se um menor número de espécies (54\%) em nosso levantamento. A maior diferença foi detectada para Amphisolenia com observação de somente 9\% das espécies registradas por Balech (1988), e a menor diferença foi para Ornithocercus (71\%) seguida de Dinophysis (65\%).
Um menor número de espécies em nosso trabalho seria esperado, considerando-se que o presente estudo é mais restrito espacialmente e temporalmente do que o primeiro.

As espécies de Dinophysiales encontradas no presente estudo também foram registradas por Balech (1988), com exceção de Dinophysis odiosa. Como o autor observou D. odiosa no Golfo do México (Balech 1967), pode-se supor que, de fato, Balech não observou esta espécie na região do Oceano Atlântico Sudoeste. Como D. odiosa foi registrada na região Central do Brasil (Tenenbaum et al. 2007), pode-se levantar a hipótese sobre a sua presença mais recente, e que estudos aprofundados sobre a ordem Dinophysiales poderiam auxiliar na compreensão dos processos que determinam a biodiversidade de dinoflagelados. Na região Central do Brasil, o número de espécies de Dinophysis (incluindo Phalacroma) é menor (19) do que o observado no presente trabalho (32), mas o número de espécies de Ornithocercus (7) e de Histioneis (10) foi significativamente maior, fato que pode ser explicado pela sua distribuição oceânica e preferencialmente tropical (Gomez 2007).

Das espécies registradas em amostras de inverno e de verão, cinco são potencialmente tóxicas, Dinophysis acuminata, D. caudata, $D$. fortii, D. mitra e D. tripos e, em amostras de inverno, ainda foi registrada Dinophysis rotundata. Destas, ressalta-se o grande número de D. acuminata durante o verão de 2007 em CSMG. Este período coincidiu com a floração de $D$. cf. acuminata (janeiro de 2007; $5210^{3}$ céls. $\mathrm{L}^{-1}$ ) em área de maricultura no estado de Santa Catarina, com mais de 300 casos de intoxicação por DSP e grandes perdas para a maricultura (Proença et al. 2007). A presença de D. acuminata e de D. fortii em área de maricultura em Santa Catarina, e a importância de seu monitoramento e estudo também foram destacados por Tavares et al. (2009), uma vez que os processos que determinam a sua concentração e produção de toxinas ainda são pouco conhecidos. Por ocasião de nosso estudo em fevereiro de 2007, a elevada densidade celular de D. acuminata na região do CSMG, coincidiu com uma intrusão na zona eufótica de Água Central do Atlântico Sul (ACAS), oriunda da mistura de águas de origem subantártica da Corrente das Malvinas e das águas tropicais da Corrente do Brasil (L. Haraguchi, dados não publicados). A presença de águas mais frias e ricas em nutrientes na plataforma continental na maior parte das estações de CSMG provavelmente esteve associada com a elevada abundância de D. acuminata, espécie de águas frias e temperadas mais abundante em águas costeiras eutrofizadas (Balech 1988, Taylor et al. 2004). Além disto, a presença de $D$. fortii, característica de águas quentes da Corrente do Brasil (Balech 1988), fazem desta uma área propícia ao desenvolvimento de espécies potencialmente tóxicas de Dinophysis, e o estudo das massas de água deve necessariamente acompanhar o monitoramento das zonas de maricultura na região.

Algumas espécies apresentaram grande variação morfológica no presente estudo, dificultando a sua identificação como morfo-espécie. Foi observada uma variação sazonal, por exemplo, em Dinophysis schroederi, cujas células eram mais robustas e com formato mais anguloso em amostras de inverno, comparadas com as células mais alongadas, de corpo mais arredondado em amostras de verão, da mesma forma como havia sido observado por Balech (1988). Este autor considera D. schroederi como um morfotipo intermediário, em uma série que varia entre os extremos boreal $D$. acuta e austral D. truncata. A mudança ambiental sazonal que ocorre na plataforma continental do sul do Brasil possivelmente está relacionada com a variação morfológica observada. Por outro lado, o indivíduo identificado como Histioneis cymbalaria era de tamanho maior do que descrito por Balech (1988), mais próximo ao tamanho de H. mitchellana; porém, optamos pela classificação $H$. cymbalaria devido a sua morfologia. As diferenças entre o tamanho e a morfologia dos indivíduos foram destacadas por Gomez (2007), que agrupou 
Tabela 1. Espécies encontradas em estações costeiras (C), de plataforma continental (P) e oceânicas (O) nos períodos de inverno de 2005 e verão de 2007 nas regiões de Albardão-Chui (A), Cabo de Santa Marta Grande (S) e nas duas localidades (D).

Table 1. Species observed in the Southern Brazilian coastal stations (C), on the continental shelf (P) and oceanic (O) areas in the Winter 2005 and Summer 2007 off Albardão-Chui (A), Santa Marta Grande Cape (S) and in both locations (D).

\begin{tabular}{|c|c|c|c|c|c|c|}
\hline & \multicolumn{3}{|c|}{ Inverno } & \multicolumn{3}{|c|}{ Verão } \\
\hline & $\mathbf{C}$ & $\mathbf{P}$ & $\mathbf{O}$ & $\mathbf{C}$ & $\mathbf{P}$ & $\mathbf{O}$ \\
\hline Amphisolenia bidentata Schröder & - & - & - & - & A & - \\
\hline Dinophysis acuminata Claparède \& Lachmann & $\mathrm{D}$ & $\mathrm{D}$ & $\mathrm{D}$ & $\mathrm{S}$ & $\mathrm{S}$ & $S$ \\
\hline D. amandula Sournia & - & A & - & - & $\mathrm{S}$ & $\mathrm{S}$ \\
\hline D. amphora Balech & - & - & - & - & $\mathrm{S}$ & - \\
\hline D. bibulbus Balech & - & - & - & - & $\mathrm{D}$ & - \\
\hline D. brevisulcus Tai \& Skogsberg & - & $\mathrm{D}$ & - & - & - & - \\
\hline D. caudata Saville-Kent & $\mathrm{D}$ & $\mathrm{D}$ & $\mathrm{D}$ & A & A & - \\
\hline D. caudata f. diegensis & - & A & A & - & - & - \\
\hline D. circumsutum (Karsten) Balech & - & A & - & - & - & - \\
\hline D. doryphora (Stein) Abe & - & $\mathrm{S}$ & $\mathrm{D}$ & $\mathrm{S}$ & $\mathrm{D}$ & $\mathrm{D}$ \\
\hline D. dubia Balech & - & - & $\mathrm{S}$ & - & $\mathrm{S}$ & $\mathrm{S}$ \\
\hline D. exígua Koifoid \& Skogsberg & - & - & A & $\mathrm{S}$ & $\mathrm{D}$ & $\mathrm{D}$ \\
\hline D. fortii Pavillard & $\mathrm{S}$ & $\mathrm{S}$ & $\mathrm{S}$ & - & $\mathrm{D}$ & - \\
\hline D. hastata Stein & - & $\mathrm{S}$ & - & - & A & A \\
\hline D. laevis Claparède \& Lachmann & - & $\mathrm{S}$ & - & - & - & - \\
\hline D. microstrigilisformis Abe & - & A & - & - & - & - \\
\hline D. minuta (Cleve) Balech & - & A & - & - & - & - \\
\hline D. mitra Schütt & - & $\mathrm{S}$ & - & - & $\mathrm{D}$ & $\mathrm{D}$ \\
\hline D. mucronata (Kofoid \& Skogsberg) Sournia & - & A & A & - & - & - \\
\hline D. nias Karsten & - & $\mathrm{S}$ & A & - & - & - \\
\hline D. odiosa (Pavillard) Tai \& Skogsberg & - & $\mathrm{S}$ & - & - & $\mathrm{C}$ & - \\
\hline D. operculoides (Schütt) Balech & - & $\mathrm{D}$ & $\mathrm{S}$ & - & $\mathrm{D}$ & $\mathrm{D}$ \\
\hline D. ovata Claparède \& Lachmann & - & $\mathrm{D}$ & A & $\mathrm{S}$ & $\mathrm{S}$ & $\mathrm{S}$ \\
\hline D. parvula (Schütt) Balech & - & $\mathrm{D}$ & A & - & $\mathrm{S}$ & $\mathrm{D}$ \\
\hline D. punctata Jörgensen & - & - & - & - & $\mathrm{S}$ & - \\
\hline D. pusilla Jörgensen & - & A & $\mathrm{S}$ & $\mathrm{S}$ & $\mathrm{S}$ & - \\
\hline D. rapa Stein & - & - & - & - & - & $\mathrm{S}$ \\
\hline D. rotundata Claparède \& Lachmann & - & $\mathrm{D}$ & - & - & - & - \\
\hline D. schroederi Pavillard & $\mathrm{S}$ & $\mathrm{S}$ & $\mathrm{S}$ & - & A & $\mathrm{D}$ \\
\hline D. schuetti Murray \& Whitting & - & $\mathrm{S}$ & $\mathrm{S}$ & - & A & A \\
\hline D. scrobiculata Balech & - & $\mathrm{D}$ & $\mathrm{D}$ & A & A & - \\
\hline D. similis Kofoid \& Skogsberg & - & - & - & - & - & $\mathrm{D}$ \\
\hline D. tripos Gourret & - & - & - & $\mathrm{S}$ & $\mathrm{S}$ & - \\
\hline Histioneis cymbalaria Stein & - & - & - & - & $\mathrm{S}$ & - \\
\hline H. hyalina Kofoid \& Michener & - & - & - & $\mathrm{S}$ & $\mathrm{S}$ & A \\
\hline H. megalocopa Stein & - & $\mathrm{S}$ & $\mathrm{S}$ & - & - & $\mathrm{D}$ \\
\hline H. milneri Murray \& Whitting & - & - & - & - & - & A \\
\hline H. para Murray \& Whitting & - & - & A & - & - & - \\
\hline Ornithocercus heteroporus Kofoid & - & - & - & - & - & $S$ \\
\hline O. magnificus Stein & - & $\mathrm{S}$ & $\mathrm{S}$ & - & $\mathrm{S}$ & $\mathrm{D}$ \\
\hline O. splendidus Schütt & - & - & $\mathrm{S}$ & - & - & $\mathrm{S}$ \\
\hline O. steinii Schütt & - & $\mathrm{S}$ & - & - & - & - \\
\hline O. thumii (Schmidt) Kofoid \& Skogsberg & - & - & $\mathrm{S}$ & - & - & - \\
\hline
\end{tabular}


as espécies de Histioneis com base em similaridades morfológicas, devido à escassez de estudos sobre a variabilidade intra-específica e o uso de muitos sinônimos. Reguera et al. (2007) mostram que $D$. caudata e $D$. diegensis fazem parte do ciclo de vida da mesma espécie, devendo ser consideradas como D. caudata f. diegensis. No mesmo artigo, a autora argumenta que as variações de tamanho e de forma derivam de seu comportamento alimentar e do ciclo de vida, pois modificações ocorrem naturalmente com a idade celular. Entretanto, as baixas densidades celulares da maioria das espécies de Dinophysiales em meio natural, ainda dificultam o avanço do conhecimento. É de consenso que a identificação de morfo-espécies necessita ser complementada com estudos genéticos e idealmente, também com o seu ciclo de vida, mas no caso de Dinophysiales, estas abordagens estão recém iniciando (Jensen \& Daugbjerg 2009).

Estudos sobre os parâmetros físico-químicos relacionados com a distribuição dos organismos no ambiente marinho são importantes para o conhecimento sobre a sua biogeografia. Na região de estudo, foram observadas diferenças temporais e espaciais na composição da assembléia de Dinophysiales, observando-se uma grande riqueza nas estações costeiras, de plataforma continental e águas oceânicas no período de verão. Neste período, águas tropicais da Corrente do Brasil apresentam influência máxima no Sul do Brasil ao passo que no inverno, as águas de origem subantártica se estendem ao norte trazendo consigo as espécies de águas frias. Assim, verifica-se que a dinâmica sazonal das massas de água é de grande importância na distribuição dos dinoflagelados Dinophysiales na região Sul de Brasil.

\section{Agradecimento}

O presente estudo foi financiado com recurso do CNPQ, através de projeto PRONEX-FURG, e bolsa PIBIC-FURG para Lumi Haraguchi.

\section{Referências Bibliográficas}

BALECH, E. 1967. Dinoflagellates and tintinnids in the northeastern Gulf Mexico. Bull. Mar. Sci. 17(2):280-288

BALECH, E. 1988. Los Dinoflagelados del Atlantico Sudoccidental. Instituto Español de Oceanografia, Madrid. Publicaciones Especiales.

CARPENTER, E.J. 2002. Marine cyanobacteria symbioses. Biology and environment: Proc. R. Irish Acad. 102B(1):15-18.

FERNÁNDEZ, M.L., REGUERA, B.R., GONZÁLEZ-GIL, S. \& MÍGUEZ, A. 2006. Pectenotoxin-2 in single-cell isolates of Dinophysis caudata and Dinophysis acuta from the Galician Rías (NW Spain). Toxicon 48:477-490.

GOMEZ, F. 2007. Synonymy and biogeography of the dinoflagellate genus Histioneis (Dinophysiales: Dinophyceae). Int. J. Trop. Biol. 55(2):459-477.

HALLEGRAEFF, G.M. \& LUCAS, I.A.N. 1988. The marine dinoflagellate genus Dinophysis (Dinophyceae): photosynthetic, neritic and nonphotosynthetic, ocean species. Phycologia, 27: 25-42.
JENSEN, M.H. \& DAUGBJERG, N. 2009. Molecular phylogeny of selected species of the order Dinophysiales (Dinophyceae) - Testing the hypothesis of Dinophysioid radiation. J. Phycol. 45:1136-1152.

KÄSLER, R. 1938. Die Verbreitung der Dinophysiales im Südatlantischen Ozean. Wiss. Ergebn. Deutschen Atlantishe Exped. Meteor 1925-27(12):165-237.

NAGAI, S., NISHITAMI, G., TOMARU, Y. \& SAKIYAMA, S. 2008. Predation by the toxic dinoflagellate Dinophysis fortii on the ciliate Myrionecta rubra and observations of sequestration of ciliate chloroplasts. J. Phycol. 44:909-922.

PARK, M.G., KIM, S., KIM, H.S., MYUNG, G., KANG, Y.G. \& YIH, W. 2006. First successful culture of the marine dinoflagellate Dinophysis acuminata. Aquat. Microb. Ecol. 45:101-106.

PROENÇA, L.A.O., SCHMITT, F., SILVA, M., GUIMARÃES, S. \& RÖRIG, L.R. 1999. Produção de ácido okadaico, uma toxina diarréica, por Dinophysis acuminata em Santa Catarina. Atlântica 19:121-127.

PROENÇA, L.A.O., SCHRAMM, M.A., TAMANAHA, M.S. \& ALVES, T.P. 2007. Diarrhoetic shellfish poisoning (DSP) outbreak in Subtropical Southwest Atlantic. Harmful Algal News 33:19-20.

REGUERA, B.R. 2003. Biología, autoecología y toxicología de las principales espécies del genero Dinophysis associadas a episódios de intoxicación diarreogénica por bivalvos (DSP). Tese de doutorado, Universidad de Barcelona, Barcelona.

REGUERA, B.R., GONZÁLEZ-GIL, S. \& DELGADO, M. 2007. Dinophysis diegensis is a life history stage of Dinophysis caudata (Dinophyceae, Dinophysiales). J. Phycol. 43:1083-1093.

SCHILLER, J. 1933. Dinoflagellatae (Peridiniae) in monographischer Behandlung. In Kryptogamen-Flora von Deutschland, Östereich und der Schweiz (L. Rabenhort, ed.). Akademischer Verlag, Leipzig.

SEELIGER, U., ODEBRECHT, C. \& CASTELLO, J.P. 1998. Os ecossistemas costeiro e marinho do extremo sul do Brasil. Editora Ecoscientia, Rio Grande.

TAVARES, J.F.R., PROENÇA, L.A.O. \& ODEBRECHT, C. in press. Assessing the harmful microalgae occurrence and temporal variation in a coastal aquaculture area, southern Brazil. Atlantica.

TAYLOR, F.J.R., FUKUYO, Y., LARSEN, J. \& HALLEGRAEFF, G.M. 2004. Taxonomy of harmful dinoflagellates. In Manual on Harmful Marine Microalgae (G.M. Hallegraeff, D.M. Anderson \& A.D. Cembella, eds.). UNESCO Publishing, Paris, p. 389-432.

TENENBAUM, D.R. 2006. Dinoflagelados e Tintinídeos da região central da Zona Econômica Exclusiva Brasileira. Museu Nacional, Rio de Janeiro, p. 111-150.

TENENBAUM, D.R., GOMES, E.A.T. \& GUIMARÃES, G.P. 2007. Microorganismos planctônicos: pico, nano e micro. In Características hidrobiológicas da região central da Zona Econômica Exclusiva Brasileira (Salvador, BA, ao Cabo de São Tomé, RJ) (J.L. Valentin, org.). Ideal Gráfica e Editora, Brasília, DF, p. 83-124.

TOMAS, C.R. 1996. Identifying marine diatoms and dinoflagellates. Academic Press, New York.

Recebido em 20/11/2009

Versão reformulada recebida em 08/07/2010

Publicado em 23/07/2010 